\title{
La fortaleza de Qal'at 'Abd as-Salam. La recuperación de una dignidad perdida (Alcalá de Henares, Madrid)
}

\author{
The fortress of Qal'At 'Abd As-Salam. Recovering the lost dignity \\ (Alcalá de Henares, Madrid)
}

\author{
Miguel Ángel López Marcos \\ Terra-Arqueos, S.L \\ e-mail: mlopezmarcos@yahoo.es \\ Manuel María Presas Vías \\ Elena Serrano Herrero \\ Mar Torra Pérez \\ T.A.R., Soc. Coop. Mad.
}

\begin{abstract}
RESUMEN
La fortaleza de fundación musulmana situada al suroeste de Alcalá de Henares (Madrid) ha sido un yacimiento arqueológico maltratado por el tiempo y por el hombre. Tras las primeras intervenciones de excavación y restauración realizadas, fue abandonado de nuevo hasta la puesta en práctica de las obras de revalorización que se realizan en la actualidad. Excavación y conservación se solapan en su ejecución con el apoyo de estudios previos historiográficos y del análisis de los factores de alteración o del estado de conservación. Se garantiza, de esta forma, que las actuaciones tengan un sentido, un objetivo claro donde prime el respeto al yacimiento y la exhibición social de un recinto fortificado con unas características propias que lo definen. Las actuaciones se ejecutan sin ocasionar alteraciones fisionómicas colaterales en nombre de la preservación del lugar. Se presentan dichas características constructivas y defensivas del cerro y del entorno al amparo de su exhibición al público como obra referente de la arquitectura andalusí en la meseta. Como tal debe recuperar su dignidad hasta hoy perdida.
\end{abstract}

Palabras clave: Poliorcética; hisn; qal'at; al-muhandis; "descarbonatación"; secuencia estratigráfica; materiales cerámicos.

\begin{abstract}
The Muslim founded fortress, placed to the Southwest of Alcalá de Henares (Madrid), has been an archaeological site roughly handled by time and men. After having been firstly excavated and restored, this site was abandoned again until the undertaking of the current reassessment tasks. Excavation and conservation tasks overlap to each other along with previous historiographical studies and analyses of factors of variations and state of preservation. It is thus guaranteed that all these activities make sense and have a clear objective, including the respect to the site and the social display of a fortified enclosure with specific characteristics. These changes do not entail formal additional modifications on behalf of preserving the place. Those building and defensive features of the hill and the surrounding areas are explained considering the social display of a monument thought to be a model of alAndalus architecture in the Iberian plateau. It is within this idea that it must recover its lost dignity.
\end{abstract}

Keywords: poliorcetica; hisn; qal'at; al-muhandis; decarbonated; stratigraphic sequence; ceramic materials.

Recibido: 21/08/2013. Aceptado: 23/10/2013.

Cómo citar este artículo / Citation

López Marcos, M. Á., Presas Vías, M. M., Serrano Herrero, E. y Torra Pérez, M. 2013: “La fortaleza de Qal’at ‘Abd as-Salam. La recuperación de una dignidad perdida (Alcalá de Henares, Madrid)", Arqueología de la Arquitectura, 10: e003. doi: http://dx.doi.org/10.3989/arq.arqt.2013.017

\section{Copyright}

(c) 2013 CSIC. Este es un artículo de acceso abierto distribuido bajo los términos de la licencia Creative Commons Attribution-Non Commercial (by-nc) Spain 3.0. 


\section{NTRODUCCI ÓN}

Desde el año 2009 se están realizando una serie de actuaciones arqueológicas en el yacimiento de Alcalá la Vieja. A partir de la documentación de una amplia secuencia de ocupación, con conjuntos cerámicos estratificados de época andalusí, y del análisis de las técnicas constructivas de la puerta de acceso, de la torre $\mathrm{n}^{\circ} 9 \mathrm{y}$ de los escasos restos de lienzos y torres conservados, se propone una nueva datación para la puerta de acceso a la fortaleza y se plantea una hipótesis del trazado y ordenamiento poliorcético del recinto fortificado para el período andalusí. Finalmente, se postulan los criterios que deben prevalecer al acometer actuaciones de conservación y restauración de los restos arqueológicos cuyo objeto no es otro que mejorar el acceso del visitante, y la comprensión del yacimiento, aplicando criterios vigentes y coherentes con la obra.

Las excavaciones realizadas entre los años 1969 y 2006 permitieron identificar una dilatada secuencia de ocupación en el cerro que abarcaba desde época prehistórica, con restos de la Edad del Bronce, hasta su abandono definitivo en el siglo XVI (Zozaya 1983'ㄹ ; Turina 1985 y 1990; Vega y Sánchez 2005 y 2009²). En cuanto a la fundación de la fortaleza, investigadores como J. Zozaya (1980, 1983), A. L. Sánchez Montes (1992) o M. A. Castillo Oreja (2006) consideran que se levantaría en torno al año 920 a partir de la identificación de al-Qulay'a con Alcalá la Vieja propuesta por E. Lévi-Provençal (1982). Este autor señala que Ibn 'Id̄ārī, en su obra al- 'Bayān alMugrib, refiere cómo en el año 920, durante la campaña de Mu'izz, 'Abd ar-Raḥmān III es informado por el gobernador de Guadalajara de una incursión leonesa contra la ciudad y el castillo vecino de al-Qulay' $a$, desastrosa para los cristianos Lévi-Provençal 1982: $362^{3}$ ). L. Torres

\footnotetext{
1 Son las primeras que se realizaron en la Meseta en una fortificación andalusí tras la guerra civil (Zozaya 1991). Sus objetivos se dirigían a confirmar hipótesis de tipo arquitectónico referidas al análisis de la estructura del castillo, a localizar la puerta de acceso principal y a documentar sus fases de ocupación. Se identifican, por primera vez en suelo madrileño, abundantes materiales cerámicos de cronología medieval (islámica y cristiana) procedentes básicamente de la excavación de tres silos.

2 Informes inéditos de las campañas arqueológicas de los años 2003 y 2006 depositados en la Dirección General de Patrimonio Histórico de la Comunidad de Madrid.

3 Nota 53 de Lévi-Provençal (1982): “indudablemente, Alcalá de Henares, situada a 26 kilómetros al suroeste de Guadalajara. Las identificaciones propuestas por E. Fagnan (Alcolea de Cinca, provincia de Huesca) y por Codera (Alcolea de las Peñas, algunos kilómetros al este de Atienza) son geográficamente indefendibles". La cita proviene de Ibn 'Id̄ārī, de su obra al- 'Bayān al-Mugrib, tomo II. Anteriormente estuvo reflejada por Ibn Hayyan en el al-Muqtabis $V$, de quien posiblemente la copia.
}

Balbás (1959), en la publicación considerada como la más relevante sobre Alcalá la Vieja hasta ese momento y título de referencia, comparte con E. Lévi-Provençal la opinión de que la mención más antigua de la fortaleza es la del año 920.

La noticia de la conquista en el año 825 del "Hisn al-qal' $a$ ” por las tropas de Faradj, señor de Guadalaja$\mathrm{ra}^{4}$, también ha llevado a plantear que estaría construida en ese año, al identificar el hisn nombrado en las fuentes con Alcalá la Vieja ${ }^{5}$ (González 1975; Pavón 1982; Turina 1985; Herrera 1985). El hallazgo casual de un dirham del 825 ha servido a numerosos investigadores para confirmar la existencia de la fortaleza en ese año ${ }^{6}$. Sin embargo, las citadas intervenciones no aportan argumentos arqueológicos que permitan defender que la construcción de la estructura defensiva se iniciara durante la época emiral.

Al margen de estas hipótesis sobre su fundación, la primera mención en las fuentes que hace clara referencia a Alcalá la Vieja, recogida por Torres Balbás, (1959) y aceptada por todos los investigadores, es la proveniente de Ibn 'Idāarī' quien indica que en agosto del año 1009 se produce una batalla en las cercanías de Alcalá de Henares (Qal'at 'Abd as-Salam), con la derrota de Wadih, gobernador de la Marca Media, contra los rebeldes beréberes partidarios de Sulayman y Sancho García. De esta forma, la existencia de la fortaleza queda acreditada con seguridad en las fuentes escritas únicamente a partir de principios del siglo XI.

\section{NTERVENCI ONES ARQUEOLÓGI CAS: 2009-2011}

Entre los años 2009-2011 se han realizado una serie de actuaciones arqueológicas que han incluido una prospección intensiva, el análisis estratigráfico preliminar de las estructuras defensivas visibles (torres y lienzo de muralla), la documentación gráfica, así como tres

\footnotetext{
Citada por Ibn 'Idāāī en Histoire de l'Afrique et de l'Espagne intitulée al-Bayano'l-l-Mogrib. Tomo II (Ibn 'Id̄ārī 1904).

5 En nuestra opinión, no queda claro que las menciones a hisn al-qal' $a$ y a al-qulay'a se correspondan con Alcalá la Vieja, ya que la primera se refiere a un lugar indeterminado ocupado por los cristianos, sin mayor referencia geográfica, y la segunda, a una fortaleza cercana a Guadalajara que podría relacionarse con Alcolea del Torote como ya defendiera Pavón (1982) al expresar sus dudas sobre la correcta identificación de Alcalá la Vieja con la fortaleza citada por Ibn 'Id̄ārī en su al- 'Bayān al-Mugrib.

6 La nómina de autores es extensa: Pavón 1982, Vázquez Madruga 1988, García Lledó 1991, 1996 y 2008, Ramírez Hernández 1998, De Diego y Canalda 2001 y De Diego 2003.

Ibidem.
} 


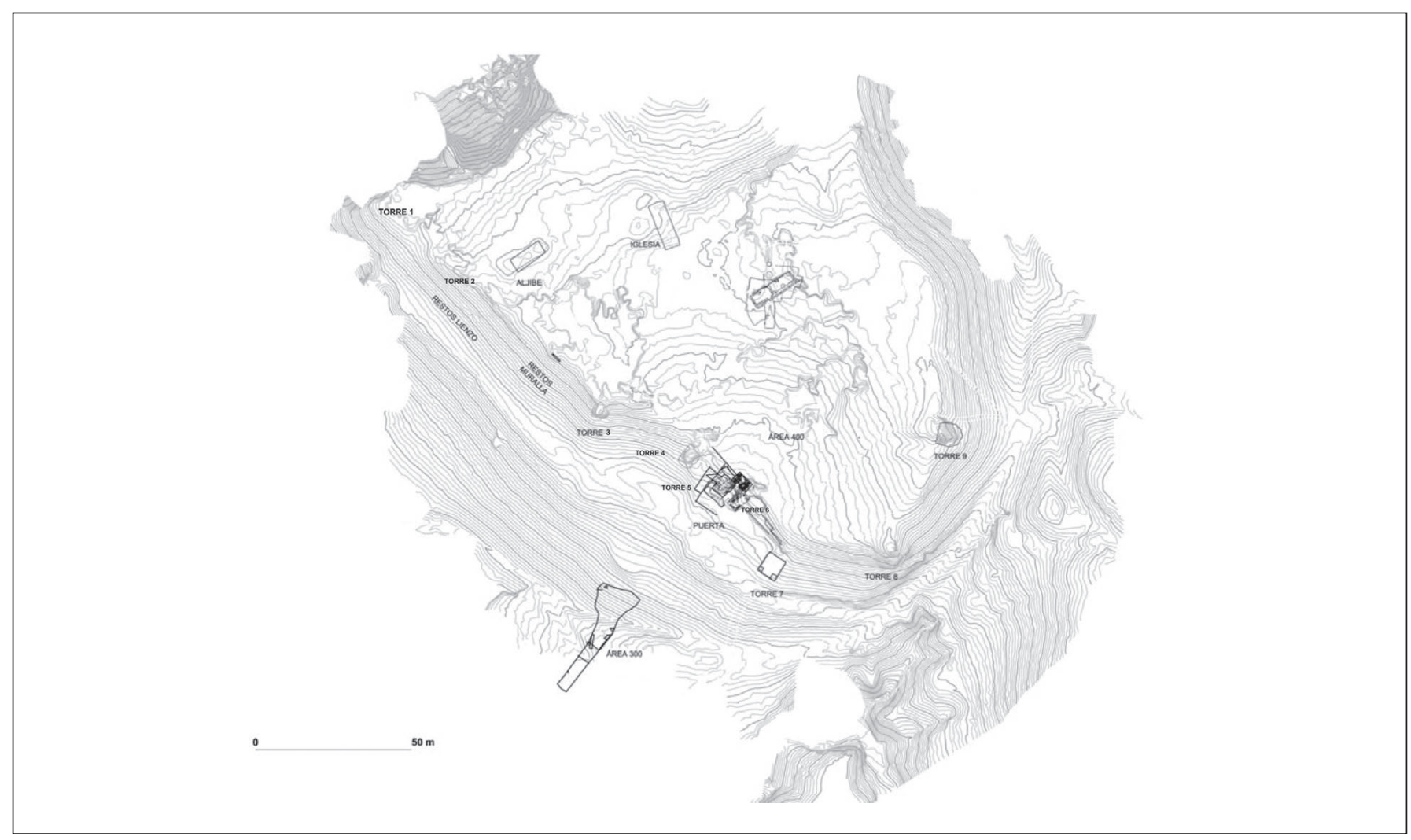

Figura 1. Alcalá la Vieja. Planta general de las excavaciones arqueológicas

campañas de excavación en sectores considerados clave del yacimiento, bajo la codirección de los autores de este escrito: en la puerta de entrada a la fortaleza, la plataforma superior intramuros ${ }^{8} \mathrm{y}$ los arrabales. En las siguientes páginas nos vamos a referir a la excavación arqueológica realizada en el área del acceso principal al recinto fortificado (Fig. 1).

La potente estratificación acumulada en el área de la puerta, intramuros, ha condicionado la estrategia de la intervención ya que ha sido necesaria la apertura de una amplia plataforma de trabajo que permitiera generar una superficie aterrazada. En este sector se ha realizado la excavación de una superficie de $450 \mathrm{~m}^{2}$ intramuros y $100 \mathrm{~m}^{2}$ extramuros (Fig. 2), trabajos que han permitido registrar, solo parcialmente, los contextos bajomedievales. Con el objeto de completar la documentación de la secuencia de ocupación se ha procedido a la excavación, en el área anexa a la puerta, de un sondeo estratigráfico, continuación de las excavaciones realizadas en el pasillo de acceso por A. Turina (1990).

\footnotetext{
$8 \quad$ Ampliación de las primeras excavaciones científicas dirigidas por Zozaya en la década de 1960 (Zozaya, 1983).
}

\section{La puerta: secuencia y propuesta de datación}

La puerta principal de la fortaleza se localizó en las excavaciones realizadas por A. Turina (1990) en la zona suroeste del perímetro amurallado ${ }^{9}$. Es una puerta de acceso directo, flanqueada por dos torres de planta cuadrangular ( $\mathrm{n}^{\circ} 5$ y 6 ) y dos arcos de herradura en el pasillo. Estas primeras intervenciones identifican una primera fase constructiva, datada en época emiral (hacia 850), caracterizada por dos torres rectangulares más estrechas y un solo arco de herradura a la que se le incorporaría, en época califal, un segundo arco. La última fase constructiva, de época cristiana, modificaría la planta de los torreones que la flanquean.

Las recientes actuaciones realizadas en el área de la puerta ${ }^{10}$ permiten, por un lado, confirmar y completar la secuencia de ocupación y por otro, proponer una nueva secuencia constructiva para la estructura defensiva a partir de un completo análisis morfológico, estructural y de las técnicas constructivas empleadas.

\footnotetext{
9 Emplazamiento que había sido apuntado por Zozaya 1983.

10 Las excavaciones a las que nos referimos en el área de la puerta son una ampliación —intramuros_ de las anteriormente comentadas.
} 


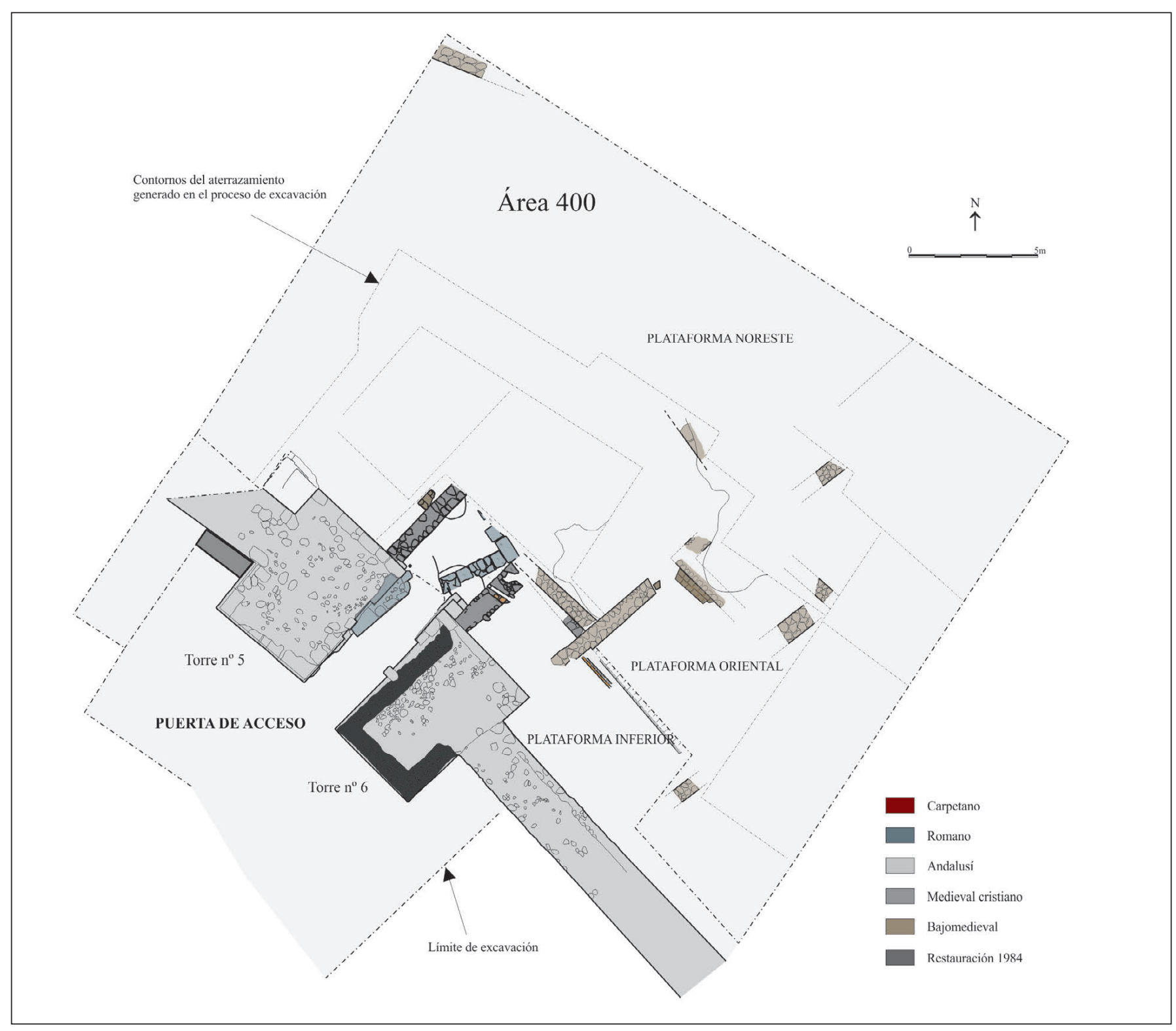

Figura 2. Área excavada en el entorno de la puerta de acceso a la fortaleza. Planta general

Se constata cómo la torre occidental $\left(\mathrm{n}^{\circ} 5\right)$ cimienta sobre una estructura preislámica conservada in situ, de probable época romana (Fig. 4). Por otro lado, en el área central anexa a la puerta, intramuros, se han documentado sendos muros con fábrica de grandes sillares, sillarejo y mampostería irregular que formarían parte de una construcción de cierta entidad ${ }^{11}$, amortizada entre finales del siglo V o inicios del siglo VI ${ }^{12}$ (Fig. 5). Para

\footnotetext{
11 La similitud de su fábrica con edificios documentados en Complutum fechados en el siglo I de nuestra era permite de momento establecer esta cronología

12 Agradecemos a Alfonso Vigil-Escalera la ayuda prestada en el análisis, revisión y propuesta de datación del conjunto cerámico procedente del estrato de amortización.
}

el periodo andalusí la primera actividad documentada se relaciona con la propia construcción de la fortaleza, en el caso que nos ocupa, la puerta principal de entrada. El amplio desmonte requerido para su construcción afecta a la compleja estratificación ${ }^{13}$, y se desmantelan y expolian, parcialmente, los muros preexistentes. Se procede a la construcción de las torres que flanquean el acceso a la fortaleza y se genera una estratificación vinculada a los diferentes niveles de uso de este acceso, desde época andalusí hasta su abandono definitivo en el siglo XVI. La superficie superior del primer estrato asociado funcionará

\footnotetext{
${ }^{13}$ Por lo que no se descarta que futuras excavaciones puedan permitir documentar nuevas fases de ocupación altomedieval.
} 


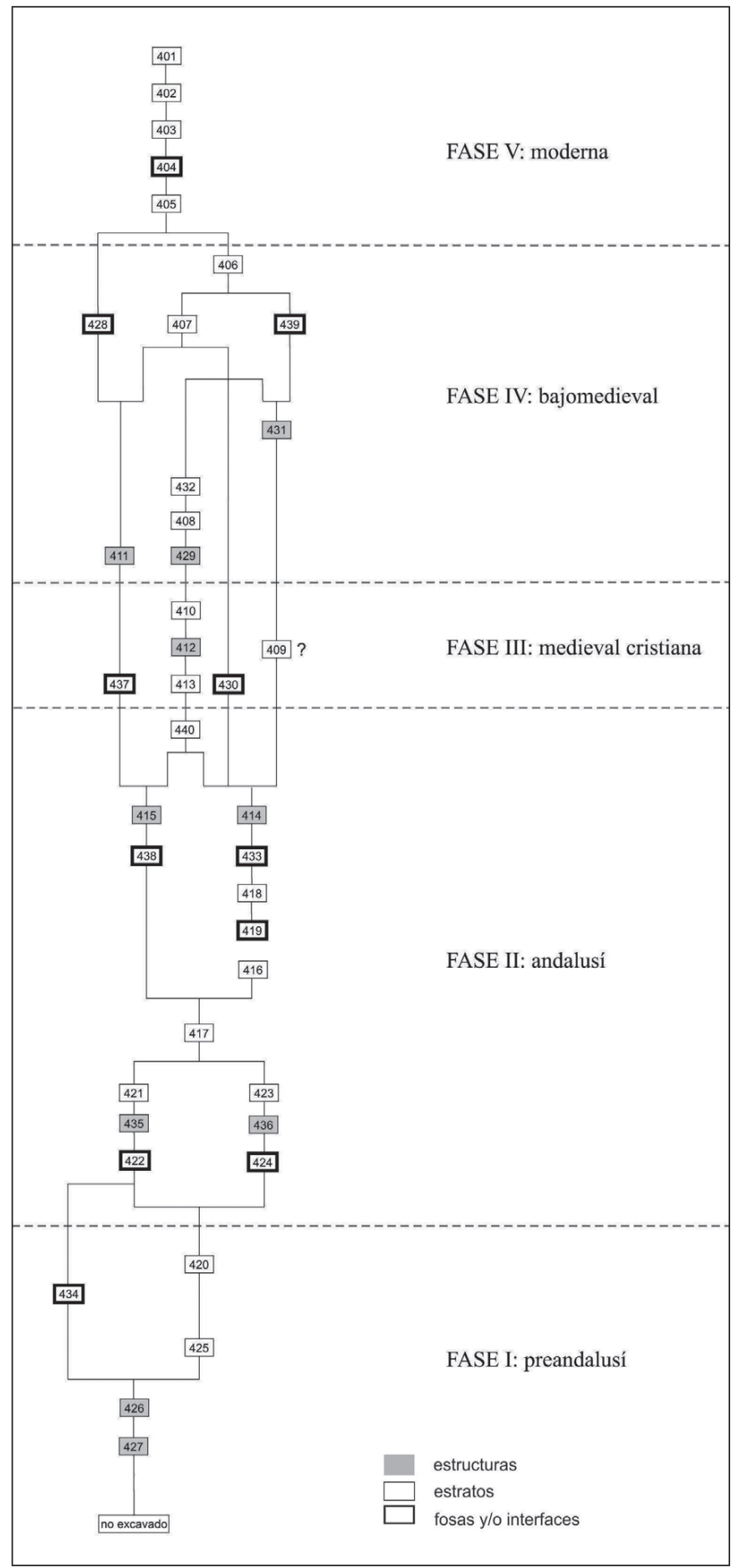

Figura 3. Diagrama estratigráfico del área 400: puerta de la fortaleza

como el primitivo nivel de uso ${ }^{14}$, al que seguirá otro, con bloques de cal y mayor dureza. El resto de la secuencia de ocupación se refiere a las fases medieval cristiana y bajomedieval a las que no nos vamos a referir.

\footnotetext{
${ }^{14}$ No se han identificado las sucesivas pavimentaciones documentadas durante la excavación del pasillo del acceso (Turina 1990: 192).
}

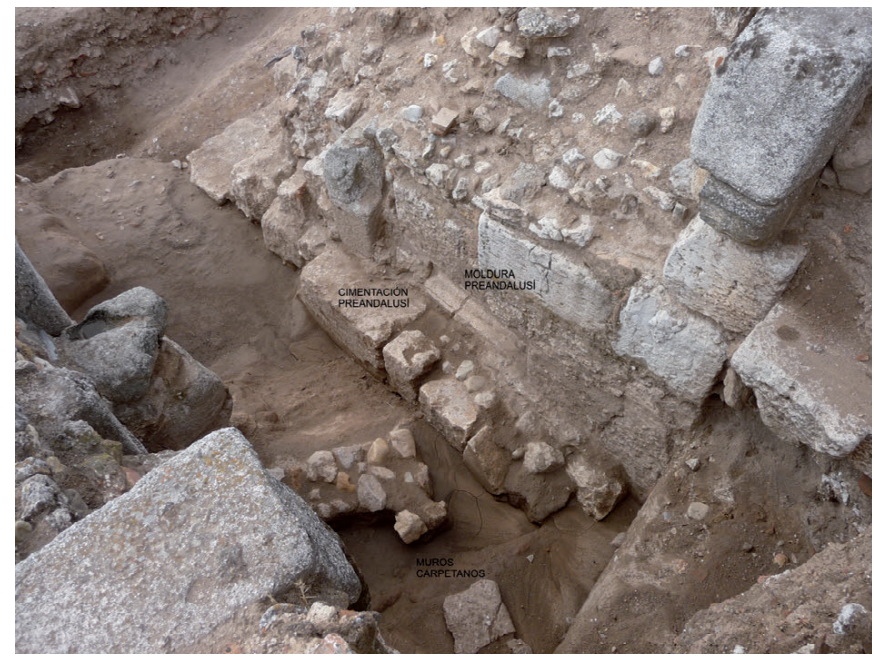

Figura 4. Estructuras preandalusíes, carpetanas y romanas, localizadas en el pasillo de entrada y bajo la torre no 5

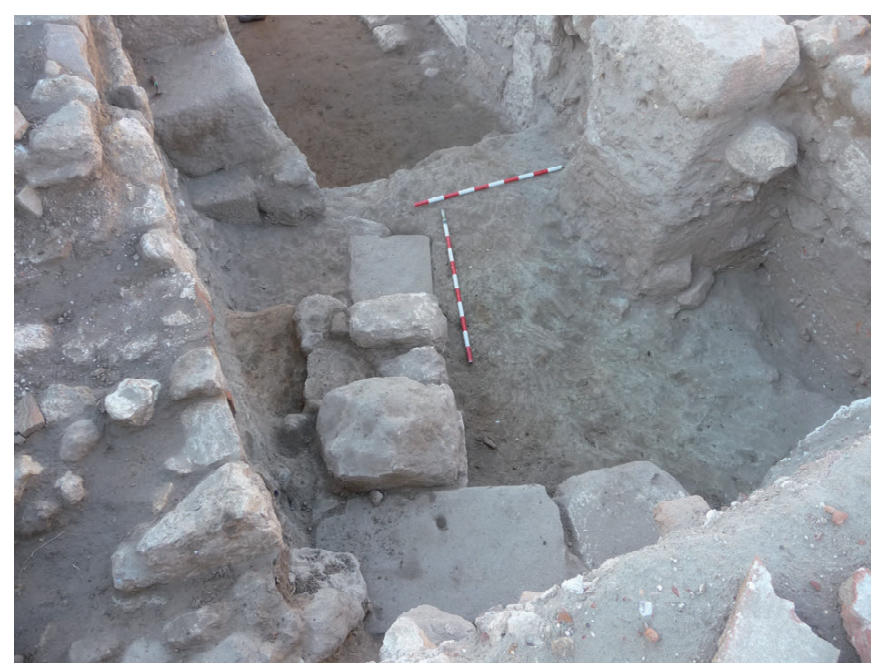

Figura 5. Muros de probable época romana localizados en el área de la puerta

Los materiales cerámicos procedentes de los rellenos de las fosas de cimentación de las torres ${ }^{15}$ (UU.EE. 421 y 423) y el primer estrato asociado ${ }^{16}$ al uso del acceso (UE. 417) se caracterizan por el incipiente desarrollo de las piezas con decoración pintada, predominio de los alisados con engobes pajizos y ausencia de ejemplares vidriados y en cuanto al repertorio morfotipológico, se identifican ollas de borde vuelto redondeado o bífido,

\footnotetext{
${ }^{15}$ Se han analizado un total de 117 fragmentos cerámicos (excluyendo el material residual que llega a representar el 14\%). Cabe destacar el engobe exterior pajizo (29\%) como acabado mayoritario y la decoración pintada con trazos rojos o negros en un $11 \%$ de los fragmentos.

${ }^{16}$ De la muestra recuperada, 144 fragmentos, cabe destacar el predominio de los fragmentos alisados (67\%), los engobes pajizos (18\%) y la decoración de trazos de pintura (11\%).
} 
jarritas de cuello cilíndrico y cuerpo globular con decoración pintada, jarras con moldura triangular en el borde y un candil de piquera. Todos los ejemplares -salvo el candil- han sido torneados y no se documentan ni ejemplares modelados a mano/torneta, ni repertorios cerámicos de tradición visigoda (Fig. 6). Para el conjunto cerámico procedente del segundo de los estratos (U.E. 416), asociado también al uso del acceso al interior de la fortaleza, cabe destacar el considerable incremento de cerámicas con decoración pintada (21\%), de ejemplares vidriados (14\%) con la documentación de las técnicas decorativas de "verde y manganeso" y "cuerda seca" sumado a la identificación de nuevos tipos como la olla con escotadura.

Sólo en fechas recientes empiezan a reconocerse secuencias de materiales cerámicos para las fases de ocupación paleoandalusíes en el centro peninsular. Las características más relevantes serían la convivencia de ejemplares torneados con otros modelados a mano/ torneta unido a la pervivencia de repertorios de tradición visigoda y a la identificación de nuevos tipos, claramente islámicos (Vigil-Escalera 2009, 2011; Olmo 2011). Sin embargo, todavía nos encontramos lejos de poder afinar cronologías, a partir del registro cerámico, para determinar qué objetos son emirales del siglo VIII d.C., del IX d.C. o del primer tercio del X d.C. (Roselló 2002: 68). Para la fase de ocupación califal, los lotes datados en el siglo $\mathrm{X}$ d.C. resultan muy numerosos, pues la documentación del sistema decorativo en verde y manganeso se emplea como un claro indicador cronológico. Con o sin "verde y manganeso", la lista de asentamientos con una clara fase califal, a partir del registro cerámico, es extensa: Guadalajara, Madrid, Calatalifa, Talamanca, Rivas, Olmos, Peñafora, Recópolis, Los Casares y un largo etc. ${ }^{17}$. En este sentido, resulta muy sugerente la hipótesis planteada por Vigil-Escalera al vincular el proceso de abandono de los pequeños asentamientos rurales, constatado a partir de la segunda mitad del siglo IX, con el auge de núcleos urbanos y centros fortificados en altura, ya se trate de pequeñas fortalezas o de enclaves fortificados con vocación urbana (VigilEscalera 2011: 197-198).

Ya hemos apuntado cómo, en nuestra opinión, las características de los repertorios cerámicos de época califal, en asentamientos donde se han documentado amplias secuencias como pueden ser los casos de Madrid o

\footnotetext{
17 Solo en algunos de estos enclaves se han documentado amplias secuencias con contextos datados desde época emiral.
}

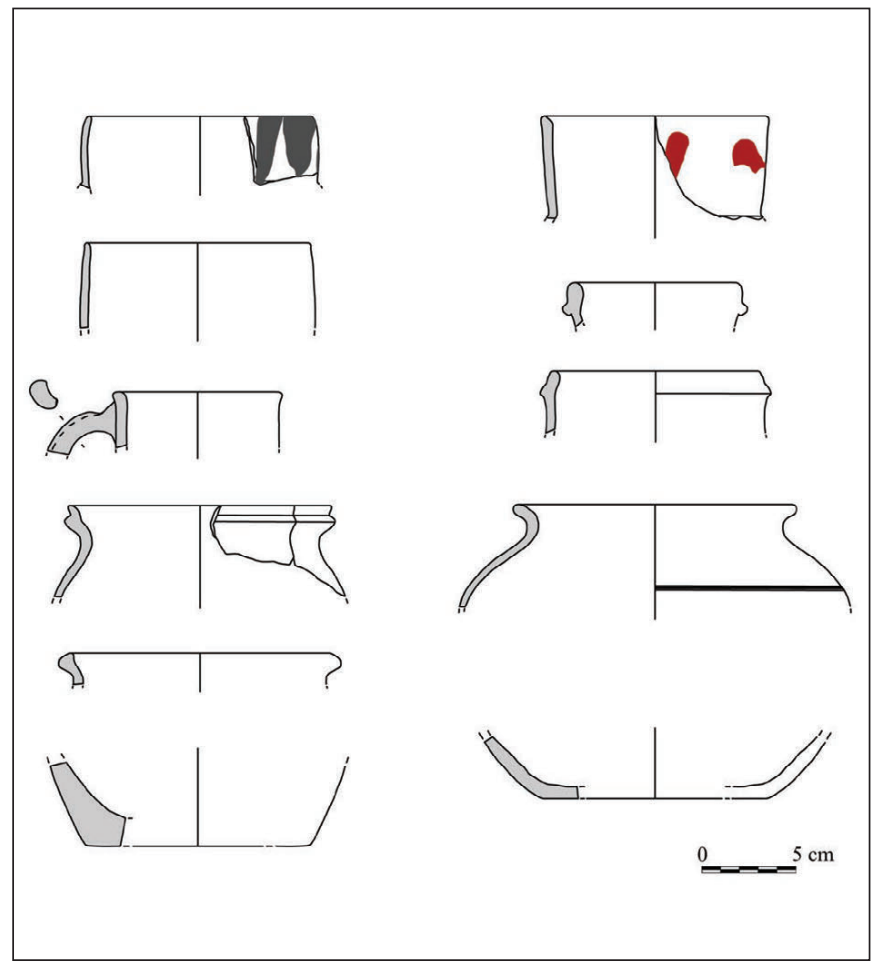

Figura 6. Materiales cerámicos procedentes del primer estrato (UE 417) asociado al uso del acceso a la fortaleza

Guadalajara, no pasa por la generalización del vidriado ni por la difusión del "verde y manganeso", como parece documentarse en otras regiones peninsulares. En el área analizada se constata una perdurabilidad de los repertorios cerámicos durante el período omeya, con introducción de nuevos tipos en fase califal, desaparición de tipos preislámicos y de piezas modeladas a mano/torneta. En el siglo XI, asistimos a la generalización del vidriado en todas su variedades (verde y manganeso, cuerda seca, monocromos y melados con trazos de manganeso), al máximo desarrollo de las decoraciones pintadas, a la introducción de nuevos tipos y a la desaparición de otros (Serrano et al. 2004; Presas et al. 2009).

Estas características de los repertorios cerámicos analizados son las que nos permiten datar en época califal la construcción de las estructuras defensivas y su primer nivel de uso y en época taifa la segunda y última fase de ocupación andalusí. Por otra parte, la lectura estratigráfica de las torres descarta la secuencia constructiva establecida por Turina (1990) y, por el contrario, permite concluir que se aprecia una clara unidad en el conjunto, que se remontaría al momento de su primera construcción (Fig. 7). Solo futuras excavaciones pueden aportar nuevos datos que completen la secuencia conocida hasta la fecha (Fig. 8). 
López Marcos, M. Á., Presas Vías, M. M., Serrano Herrero, E. y Torra Pérez, M.

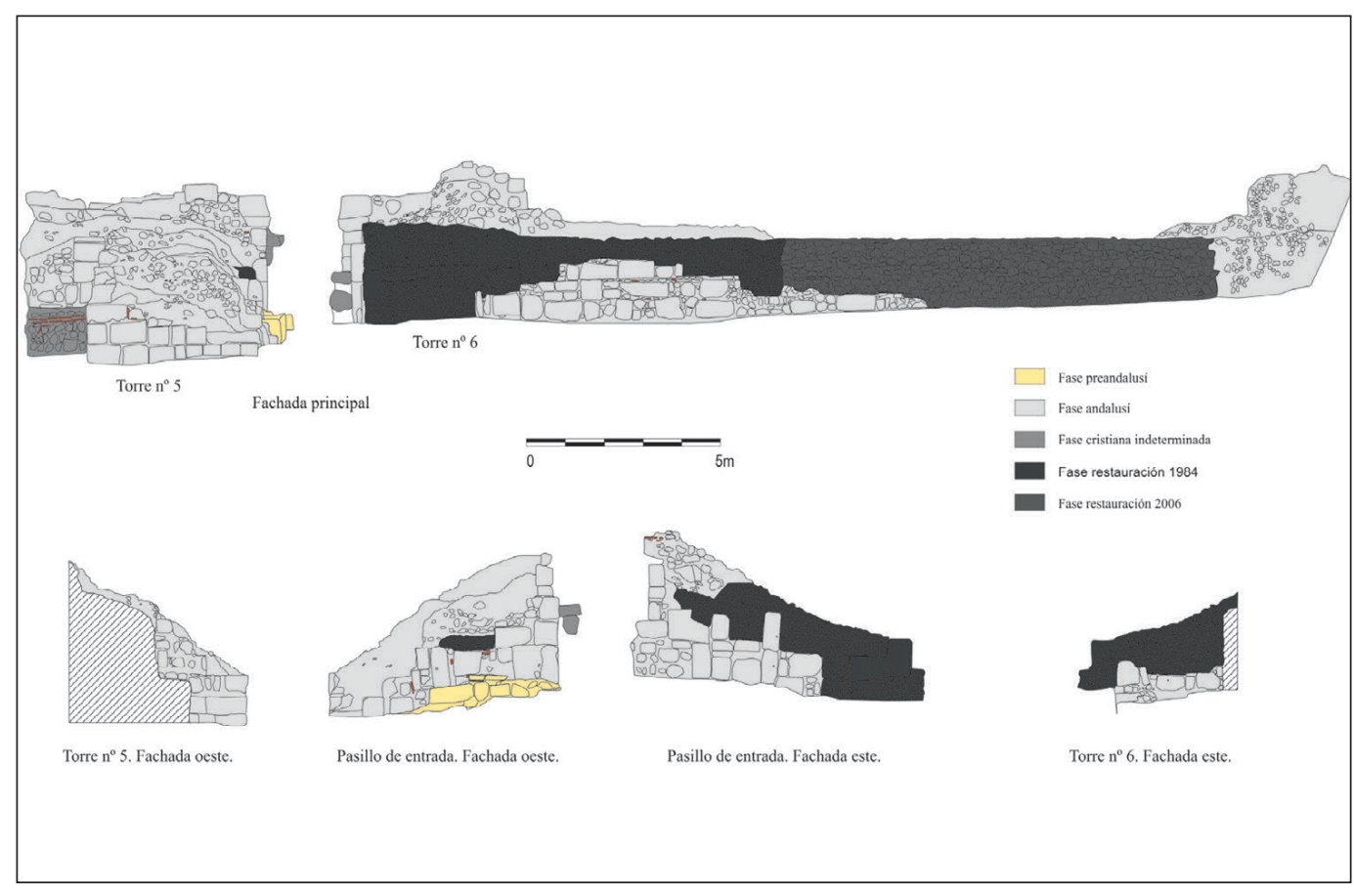

Figura 7. Alzados de la fachada principal y laterales de la puerta de entrada a la fortaleza

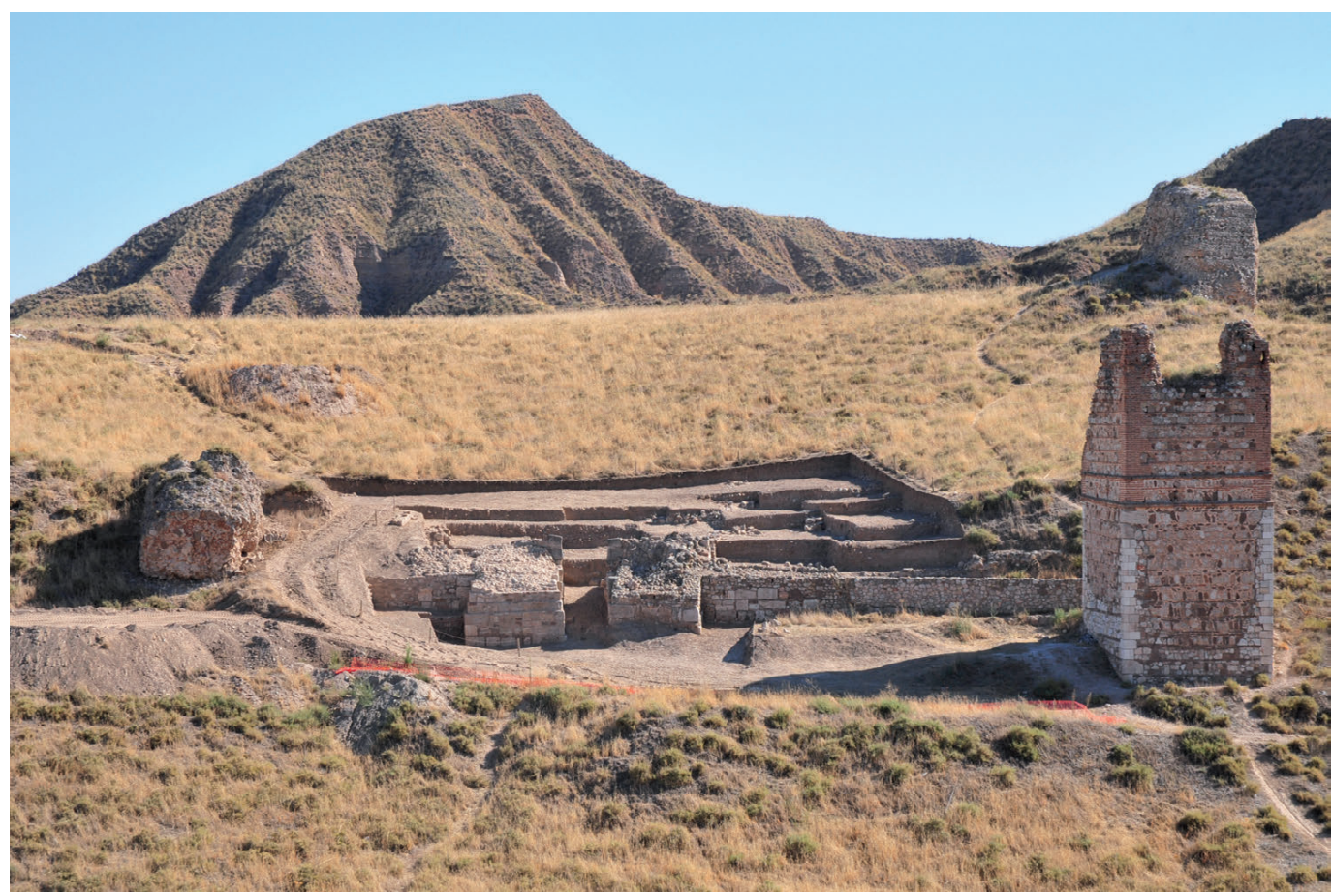

Figura 8. Vista general del área excavada en el entorno de la puerta

\section{NFLUENCI A DE LOS CONDI CI ONANTES GEOLÓGI COS}

Antes de analizar el trazado de la fortaleza o las técnicas constructivas, es necesario revisar muy por encima el influjo de la subordinación geológica a la que está sometido el asentamiento, ya que es determinante, en la forma de construir, en algunas de las reformas documentadas en el yacimiento (véase el caso de la torre número 9), o en los sucesivos procesos de alteración y consecuentes problemas de conservación de las estructuras.

La región donde se circunscribe la fortaleza constituye un paisaje de carácter continental típico del mioceno, formado por altas mesetas a diferentes niveles, que conforman un amplio ambiente de páramos, dependiendo 
Figura 9. Vista aérea del cerro donde se ubica la fortaleza en el borde del páramo, aprovechando una de las facetas triangulares del Mioceno, que facilita la defensa natural del emplazamiento

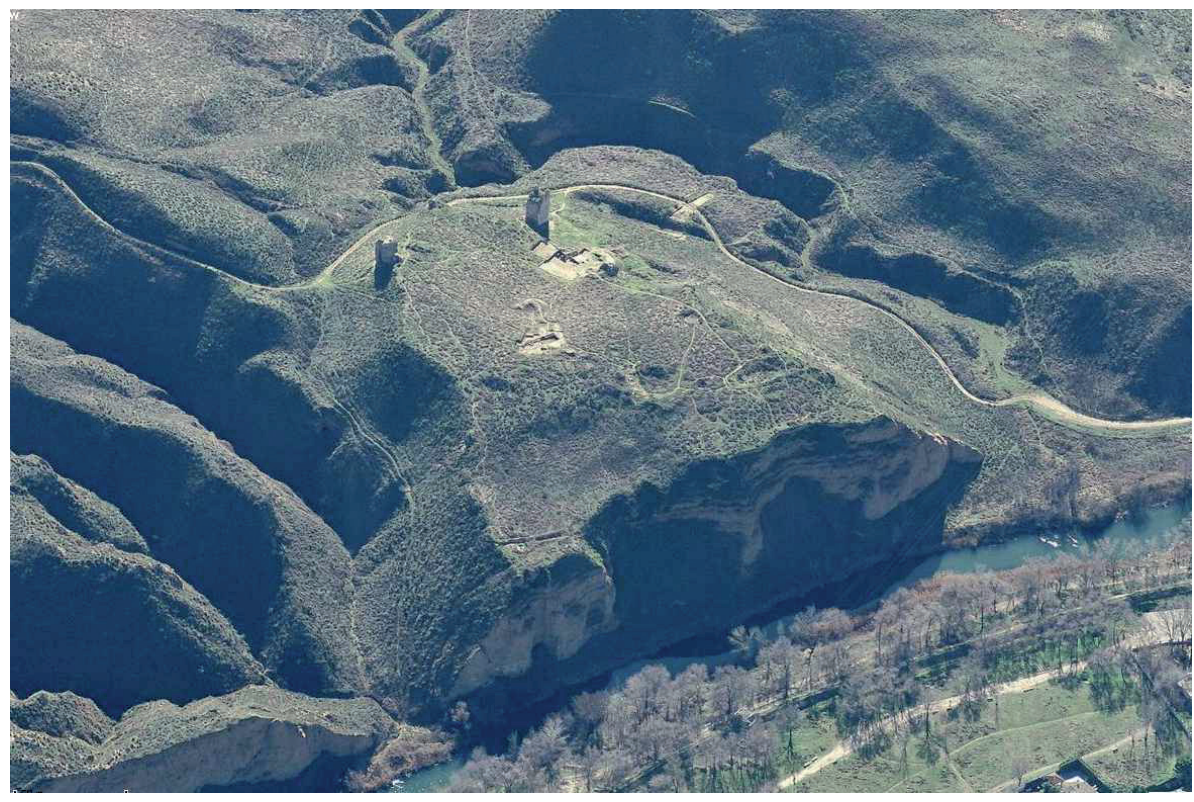

de la erosión y de los materiales que rellenan la fosa tectónica del Tajo ${ }^{18}$.

El paisaje actual se formará ya en el Cuaternario, creando un sinfín de cárcavas, barrancos y hoyas, que resultarán definitivos en la elección del lugar de asentamiento. Todo se inicia a principios del Cuaternario, cuando se genera la raña en las inmediaciones de Guadalajara, desarrollándose las redes fluviales cuaternarias, identificándose con dicha formación la primera terraza de los ríos Jarama, Sorbe, y Henares. El borde se articula en cuencas torrenciales, con los correspondientes conos de deyección a la salida de las áreas acarcavadas, donde a veces se detectan formas complejas de vertiente, como las facetas triangulares, que son pequeños testigos de la superficie original (Silva 1988 inédito).

Es precisamente en una de estas facetas triangulares donde se instala la fortaleza, aprovechando sus peculiaridades geomorfológicas, en uno de los cerros. Su característica forma triangular se adapta por tanto al borde del páramo en su vertiente más acusada al noroeste, otra de

\footnotetext{
${ }_{18}$ Aunque la formación del entorno se inicia en el Cretácico, tiene su máxima expresión en el Paleógeno y sobre todo en el Neógeno. Al noroeste se extiende el Sistema Central, rico en granitos y arcosas, e importante fuente de sedimentos de la fosa. Los sedimentos terciarios descansan sobre rocas de edad cretácica y paleógena con un espesor medio de $600 \mathrm{~m}$. A su vez se subdividen en unidades inferior, media y superior. La unidad intermedia, de unos $160 \mathrm{~m}$, aflora en el borde del páramo, donde se encuentra la fortaleza y abundan los niveles margosos, yesos, bancos de caliza, así como la llamada formación blanca, compuesta de arenas con nódulos de sílex. La unidad superior, también presente en nuestra zona de influencia y de unos $50 \mathrm{~m}$ de espesor, está formada de conglomerados, arenas, arcillas, margas y rocas carbonatadas rematadas por la llamada caliza de los páramos (Martín Escorza 1979).
}

menor pendiente, al noreste y por último, la más suave al suroeste, donde se aloja la entrada y, por supuesto, el mayor número de torres de vigilancia' ${ }^{19}$ (Fig. 9).

\section{ORDENAMI ENTO POLI ORCÉTI CO Y TRAZADO}

Se dibuja así una fortaleza de morfología peculiar al adaptarse al terreno, que aprovecha el máximo de superficie e instala murallas y torres en el borde de escarpes y cárcavas. El desconocimiento de un proceso erosivo aún activo provocó el deterioro y caída de muros y torres al descalzarse los cimientos. En el caso de la torre número 9 aún se aprecia la fuerte erosión y el recalce de época cristiana realizado con tapial y de nuevo descalzado y en peligro de caída en la actualidad.

El trazado de murallas y torres se adapta, por lo tanto, a la topografía de la meseta y la puerta principal se localiza en la zona suroeste ${ }^{20}$. Se insinúan por el

\footnotetext{
${ }_{19}$ El entorno es idóneo para el asentamiento, donde los nuevos pobladores deben habituarse a los elementos que les ofrece el terreno. Es preciso recordar que la fortaleza se sitúa en una zona rica en arenas, arcillas, y calizas. Se aprovechan por tanto como base de materia prima estos elementos para la construcción de todo tipo de estructuras, ya se trate de arquitectura militar o civil. También se encuentran materiales de importación, como los bloques de granito de la zona de acceso, que provienen sin duda del otro lado de la cuenca, ya en el Sistema Central. Es difícil saber la procedencia exacta y el momento de importación, si bien parece lógico pensar que se trate de sillares romanos reutilizados, como otros muchos de caliza que se amortizan en la construcción andalusí.

${ }^{20}$ Torres Balbás (1959) situaba en las proximidades de la torre 9 la puerta de la fortaleza. Es en las excavaciones de Zozaya (1983), cuando se interpretan los restos identificados junto a esta torre como un portillo. Finalmente, Turina (1990) localiza el acceso principal, flanqueado por dos torres (5 y 6), en el tramo suroeste.
} 
momento un total de nueve torres. La repartición se distribuye de forma desigual, con separaciones de 20 codos o de 70 codos en algunos casos, y se sitúan en las zonas más sensibles de asalto. En otro tipo de construcciones, como en Gormaz, Trujillo o Tarifa se disponen de forma ordenada (Zozaya 1992). En Qal'at 'Abd asSalam habría que pensar en la escasez de materia prima o/y en la urgencia con que se ejecutó la construcción, para justificar esta reducción al mínimo indispensable de unidades y el desajuste poliorcético que acentúa la vulnerabilidad de la fortaleza ${ }^{21}$.

El trazado es irregular, aunque la métrica aplicada en todos los tramos analizados, sin embargo, es la utilizada en la época. Fundamentalmente se distinguen dos tipos de codos islámicos: el rasasí y el mamuní o ma'muniyya. El codo rasasí mide algo más de $50 \mathrm{~cm}$ y fue introducido por Al-Râssâs en la península al utilizarlo como patrón en la mezquita de Córdoba y es el más empleado. El codo negro o mamuní mide $47 \mathrm{~cm}$ y es el más empleado en la Marca Media (Almagro 2008: 67). Ambos tienen múltiplos (caña y qala) y submúltiplos (pie, palmo, dedo) (Martínez Enamorado et al. 2007). Si bien es cierto que en este caso parece

\footnotetext{
${ }^{21}$ En asentamientos de similares características y condicionantes constructivos (Gormaz, Trujillo o Baños de la Encina), se distribuyen y alternan los paños de muralla y las torres de una forma más o menos equidistante. Se evidencia la diferencia en el trazado si se compara con este caso. Si los condicionantes son similares (visibilidad, sustrato geológico, etc.), la razón de que en algunos ocasiones se construyan torres defensivas con cierta asiduidad o equidistancia, o que en Alcalá la Vieja se distribuyan en las zonas más sensibles al asalto, demuestra que existe una austeridad constructiva, o una premura de ejecución, o una escasez de materiales y agua, o la combinación de todos los factores. La decisión de construir torres cada 20 o cada 70 codos viene determinada por la estrategia defensiva y la poliorcética, incluso por el estilismo o el gusto de la época, en casos de prosperidad, pero sin duda, está condicionada por las posibilidades de ejecución. Se puede calcular el volumen de una torre media de diez codos de base por ocho de ancho y una altura de veinticinco codos, en unos $260 \mathrm{~m}^{3}$. Todo el conjunto podría llegar a superar las 700 toneladas de peso, piedra y cal, de un material que no existe en el cerro y se debe traer de fuera. La ausencia de materia prima, sin duda condiciona la construcción, y quizás también la falta de tiempo para el transporte y ejecución de la obra. Otro de los argumentos para hablar de austeridad constructiva o premura de ejecución, se refiere al reaprovechamiento de los sillares de las zonas de acceso. Tanto la caliza, como sobre todo el granito se adapta mínimamente a la nueva construcción. De esta manera las dovelas se retallan de forma radial para completar la hoja del arco, pero las aristas se dejen rodadas e irregulares. Los sillares que conforman la jamba para sujetar los arcos se colocan uno sobre otro, sin siquiera igualar sus medidas, sin tapar antiguas quicialeras, ranguas, etc. No existe ningún cuidado en la construcción y lejos de recrearse en los acabados y en el valor estético, se centran los esfuerzos en la funcionalidad de la construcción. Es evidente que se debe hablar de austeridad constructiva o de premura en la construcción puesto que se redujo al mínimo la obra de cantería. Igualmente se delata la rapidez de ejecución en la extracción de sillares de la antigua construcción romana. En el pasillo de acceso quedan restos de sillares de gran envergadura que fueron golpeados y rotos en la zona superior para rebajar su cota superior y de esta manera eliminar obstáculos del paso.
}

que es el rasasí el empleado, es difícil establecer una correspondencia exacta ${ }^{22}$. Es preferible ser un poco más flexible, especialmente en métricas poco definidas como lo son las manejadas en la edificación de grandes estructuras. Sería más sugerente suponer un codo islámico de una equivalencia de $50 \pm 3 \mathrm{~cm}$, que oscila en un abanico de entre 47 y $53 \mathrm{~cm}$, que por otra parte es más que suficiente para el estudio de las características aquí propuestas. Para aproximarse a la verificación del codo que se haya podido manipular, es preciso buscar la referencia en el diámetro del arco de entrada, donde la concreción del módulo utilizado deja poco margen de error, a diferencia de la irregularidad general de la edificación, variable, como se ha señalado, especialmente en zarpas y primeras tongadas. Son diversos los factores que hacen indefinida la modulación de la construcción, especialmente al analizar, en su mayoría, restos de cimentación donde tiene poco sentido actuar con precisión.

El diámetro real del arco de herradura de la entrada se encuentra dos centímetros por debajo de la cota superior del salmer occidental. Alcanza los 2,098 m, que se corresponde con cuatro codos de $52,5 \mathrm{~cm}$. De este modo se encuentra la equivalencia exacta con el codo rasasí, que se mueve en la horquilla de los 52-55 $\mathrm{cm}$ de largo ${ }^{23}$. Así, se plantea un trazado de muralla de 4 codos de ancho, mientras que las torres de flanqueo en la entrada tienen una envergadura de 10 codos y 12 de fondo. El torreón número 5, situado al oeste es más grande (10 codos) que el número 6 , ubicado en la zona más al este (8 codos). La zona de paso o acceso es de 4 codos, igual que el diámetro del intradós del arranque de arco conservado, mientras que el extradós es de aproximadamente 6 codos.

Con respecto a las alturas, poco se puede decir, puesto que la torre que se conserva completa, la número 7 , es de época cristiana (sin desechar que se asiente sobre una islámica), y la número 9 presenta una altura conservada de $6,5 \mathrm{~m}$, pero no está entera ${ }^{24}$.

\footnotetext{
${ }^{22}$ Sucede algo parecido con el pie romano, que puede medir 29,6 cm en el acueducto de Segovia, o 31,5 cm en las termas de Toledo.

${ }^{23}$ Este codo, como todos, se basa en el hasimi, medido en el nilómetro de la isla de Al-Rawda en el Cairo, de 54 cm, y está inspirado en los codos egipcios de época faraónica de 52,3 cm. (Vallvé 1976).

${ }^{24}$ Pasa lo mismo con el lienzo de muralla que presenta una línea de acabado con pretil y mechinales de desagüe que corresponde a una desafortunada intervención de restauración de 1984 y 2006, y no a la altura real de la construcción muraria.
} 


\section{ANÁLISIS ESTRUCTURAL Y TÉCNI CAS CONSTRUCTI VAS}

La construcción defensiva se adapta hasta el límite de la superficie edificable. La entrada principal se sitúa en la zona de pendiente más suave para facilitar el acceso. Las torres de flanqueo arrancan sobre zarpas escalonadas para contrarrestar la pendiente, tan características en este tipo de fábricas (Almagro 2008). Toda la edificación sigue unas pautas de sencillez propias de la arquitectura militar andalusí.

Se extiende el uso de sillería mezclada con argamasas en el interior del paramento, especialmente en las regiones donde la piedra escasea. Para ello se hace necesario, en muchas ocasiones, el uso de encofrados debido a la lentitud de fraguado de la cal aérea. La ejecución de este tipo de obra obliga a evitar la línea curva en paramentos y torres en beneficio de construcciones cuadradas, rectangulares y de líneas rectas que posibiliten la tablazón para construir (Navareño 1988). Es necesario señalar que las edificaciones no se construyen previamente de tapia o argamasa para forrar el núcleo de sillares, como en ocasiones se ha interpretado huyendo de toda lógica constructiva, sino que el proceso común es el de recibir la fábrica de sillares y mampuestos, en tongadas, y se rellena al interior de argamasa para hacer una eficaz obra de resistencia masiva.

La rigidez modular tan característica de la época pierde aquí protagonismo ante la influencia de diversos factores. Por una parte, el asentamiento sobre restos de edificaciones anteriores fuerza la realización de una construcción un tanto confusa, sin pautas regladas a seguir. La línea de fachadas de las torres de acceso no se corresponde en paralelo, dibujando un desarrollo suavemente abocinado al interior. Por otra parte, la situación topográfica influye en la diferencia de tamaño entre una y otra torre, como explicaremos más adelante.

Otro de los factores que influyen en la manera de construir es la ausencia total de materia prima de calidad. El reaprovechamiento de sillares de caliza y granito, en menor medida, se hace habitual en la construcción de las zonas principales, de forma que en las torres 5 y 6 se colocan en la base y en los sectores más sensibles, mientras que en otros tramos, como es el caso de la torre número 9, los sillares empleados y reutilizados son escasos en beneficio del sistema de encofrado para la mayor parte del torreón.

Los sillares de granito se retallan para construir las hojas de arco, mientras que se reutilizan otros para pies derechos o sillares angulares sin retallar (se pueden ver varios ejemplos de bloques sin trabajar con ranguas y cotanas). Los de caliza, de menor entidad estructural, se emplean sobre todo en el recibido de paramentos. El asiento de bloques y piedra describe un aparejo mixto concertado de sillares, mampuesto y ladrillo, recibido con mortero de cal y arena de río, en proporción de 1:4, según análisis realizados a pie de obra.

El sistema empleado recrece en más de medio metro el aparejo en fachada y se rellena al interior con argamasa y piedra de pequeño tamaño, también llamado de calicanto (Navareño 1988). Esta técnica constructiva se basa en la edificación corriente de la línea de fachada en un codo aproximadamente. Si el grosor es suficiente se espera unos días y se rellena al interior con cal y canto, si bien el proceso habitual es encofrar al exterior y rellenar con seguridad sin necesidad de esperar tanto ${ }^{25}$. Para elaborar el material de amasado, se machacan piedras calizas y se calcinan, en hornos no hallados en la fortaleza hasta la actualidad, si bien es posible también su calcinación a pie de cantera. Tras el proceso de apagado se obtiene el hidróxido de calcio utilizado en la base de la argamasa. Para alcanzar el proceso de fraguado es preciso el transcurso de varios días hasta alcanzar la carbonatación necesaria (Sepulcre 2003). Este proceso se consigue en contacto con el $\mathrm{CO}_{2}$ ambiental en un período indeterminado de tiempo, nunca inferior a una semana según la reacción:

$$
\mathrm{Ca}(\mathrm{OH})_{2}+\mathrm{CO}_{2} \rightarrow \mathrm{CO} 3 \mathrm{Ca}+\mathrm{H}_{2} \mathrm{O}
$$

Tras la reacción de fraguado se forma carbonato cálcico y agua. Tanto el proceso de secado de la argamasa como el de “carbonatación” de la misma supone que, después de cada tongada de trabajo, realizada en una jornada, se debe detener la obra en esa zona, al menos, una semana.

La escasez de materia prima en otras construcciones, como es el caso de la torre número 9, obliga al encofrado directo para rellenar todo el interior con cal y canto sin sillares en fachada. En este caso el encofrado es más fuerte y sujeta directamente la argamasa y piedra aglutinada con agua del interior (30 tm). En la construcción de las torres 5 y 6 la tablazón de la armadura puede ser más débil, debido a que el empuje lateral del calicanto se reduce de forma considerable por el peso de la fábrica exterior de mampuesto y sillar.

\footnotetext{
${ }^{25}$ Es preciso tener en cuenta que en el caso de la torre 5, por ejemplo, se considera un peso de más de 30 toneladas por tongada, sin contar el del agua inicial extra, lo que explica que al soportar un peso estructural mayor (para 1,20 m más de potencia equivale aproximadamente a 90 toneladas), sea necesario ensanchar la base de cimentación para reducir superficie en altura hasta conseguir dimensiones similares a la torre oriental.
} 
En la zona de la entrada, una vez resueltos los diseños de torres y accesos, se crea un pequeño túnel de 12 codos de profundidad, que alberga la doble entrada bajo el adarve, con dos hojas de arco de 4 codos de diámetro, situadas al interior. Es necesario construir un rebaje o derrame a modo de retranqueo para embutir los batientes de la primera puerta de forma que no interrumpa el paso en un estrecho acceso de 4 codos de ancho.

Los encofrados se utilizan tanto en fábrica de mampuesto, cal y canto o tapial. Los constructores andalusíes son hábiles en el manejo de tablazones para recubrir paramentos. La técnica es sencilla, reutilizando el mismo armazón utilizado para la mampostería y la sillería según se recrece. La armadura se ata al muro y se ancla mediante agujas de madera y codales. La estructura desmontable (cajón) se compone de fronteras, costales que se ajustan con tensores (garrotes) (Monjó 1988). Esta técnica constructiva es por lo tanto la más arraigada en la tradición de quien se asienta en unos terrenos inestables para otros ${ }^{26}$. El hecho de que sean poco diestros en obras de plementería y cantería en general no es óbice para buscar este tipo de solución en los puntos más sensibles como pudiera ser el acceso al recinto (Márquez y Gurriarán 2008).

El trazado de la puerta se dibuja en parte sobre los restos de construcciones romanas preexistentes, lo que facilita el aprovisionamiento de material. La cimentación de la torre occidental apoya directamente sobre dichos restos (Fig. 10). Esto sugiere la posibilidad de que se iniciara la edificación por la torre oriental, reutilizando los sillares y mampuestos existentes. Una vez concluida la construcción de la zarpa derecha, se procedería al planteamiento de la zona occidental, buscando la cimentación a más de 1,20 m de profundidad en relación a la practicada en la anterior. Esto supone la necesidad de aumentar tres tongadas de construcción, y ensanchar la superficie de base de la obra. Es decir, se hizo necesario aumentar el material constructivo en 90 toneladas extra de peso que ocasionó el replanteamiento de la torre número 5, ensanchando en dos codos la base de la zarpa. Es importante tener en cuenta que las torres aparentan ser desiguales en fachada. La desigualdad de ocho a diez codos, entre una y otra torre, existe solamente a nivel de

\footnotetext{
${ }^{26}$ Tanto en época romana, como posteriormente en época cristiana, las instalaciones defensivas se construían en otro tipo de sustrato geológico más firme, a la vez que las obras de cimentación eran más profundas y masivas. Sin embargo, en época emiral o califal, y siempre desde un punto de vista general, se pueden constatar la existencia de fortalezas sobre terrenos arenosos, arcillosos, etc., además de realizar cimentaciones de escasa profundidad (Alcalá, Calatalifa, Madrid, etc.). En época andalusí, se construye en terrenos firmes, rocosos, o en otros menos compactos.
}

zarpa, únicos restos conservados. Seguramente en altura las dos torres tendrían unas medidas de cuatro codos de ancho cada una (Fig. 11). Sin embargo parece claro que los restos romanos condicionaron la rectificación del torreón izquierdo, abocinando la entrada hacia el interior.

La construcción se realiza de una sola vez, según un diseño y dibujo previo, siguiendo las pautas de la poliorcética califal (Souto 1997). Los gruesos sillares se reaprovechan en la zarpa para macizar torres y murallas. Si se hubiera recrecido, o reformado, o transformado en otra época, se hubiera reflejado en la separación de morteros de las tongadas, como se puede observar en la torre caída anexa, número 4 (Fig. 12). Sólo una semana es más que suficiente para dejar huella en la "carbonatación" del mortero. Esto es debido a que el nuevo mortero vertido no pega con el anterior como si fuera uno solo, sino que se junta o adhiere, presentando una zona de debilidad. Estos procesos de "carbonatación" son magníficos delatores de la obra realizada. No podemos estar de acuerdo con la

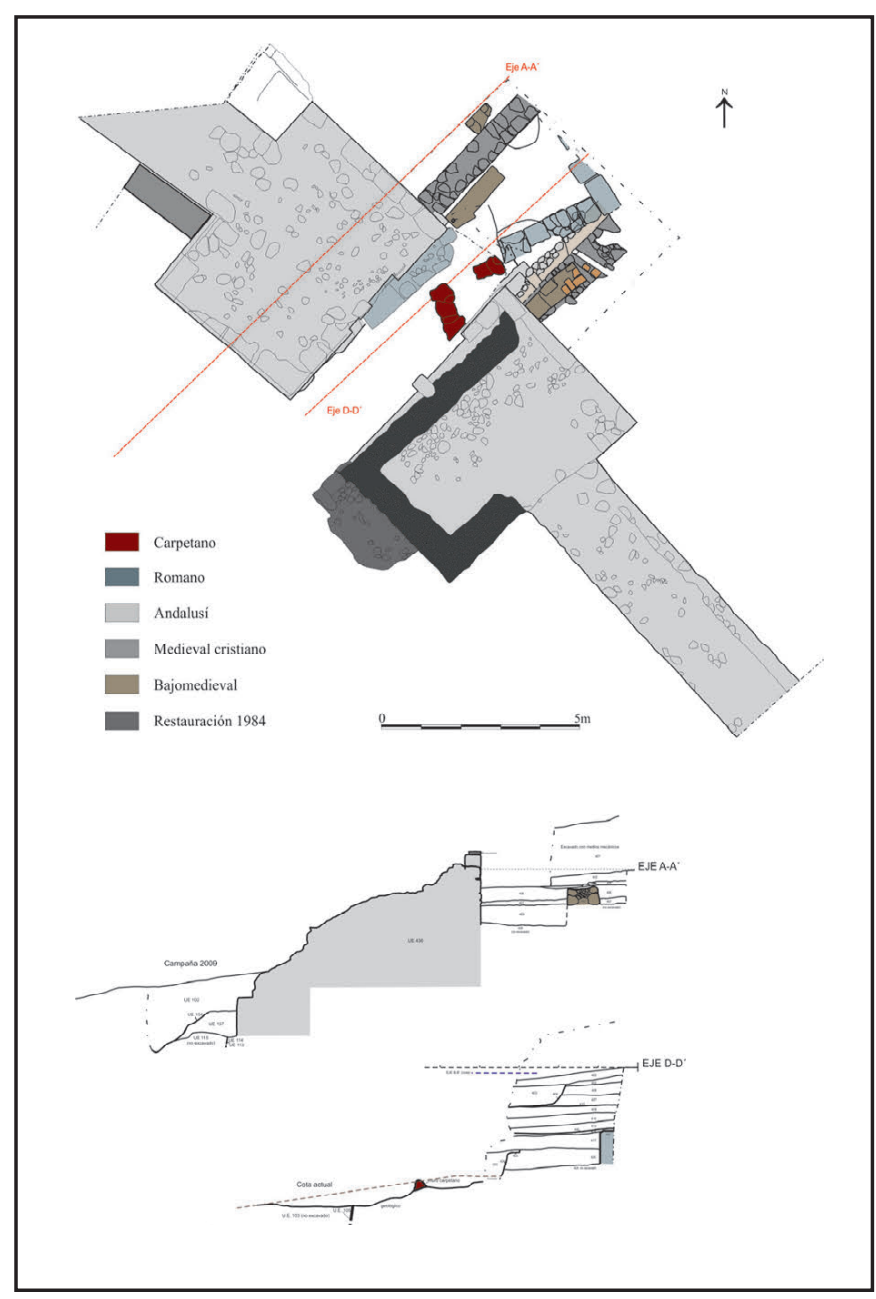

Figura 10. Planta de la zona de acceso. La diferencia de tamaño a nivel de zarpa no se corresponde con seguridad en altura al tamaño real de las torres, que debía ser el mismo 


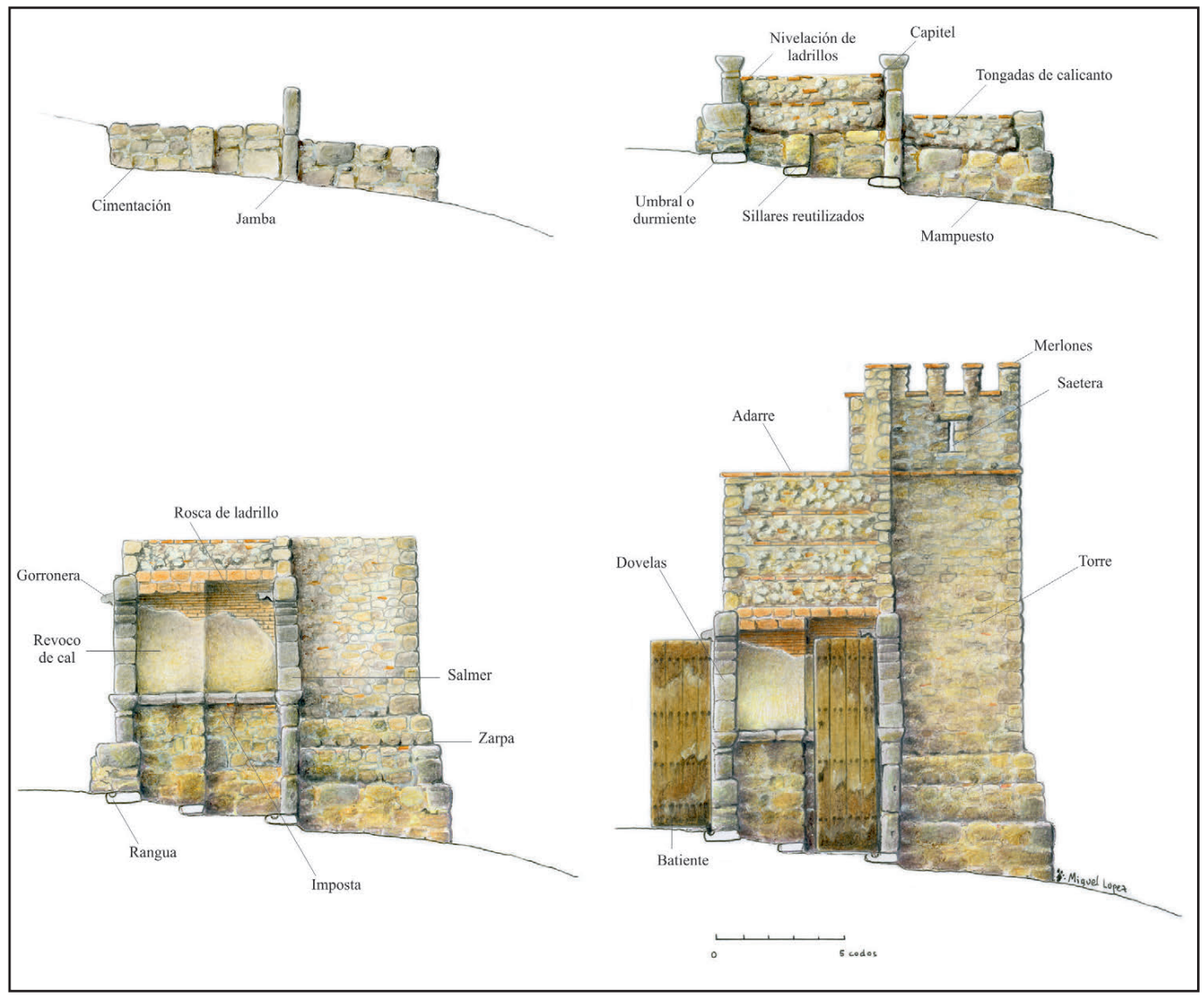

Figura 11. Alzado hipotético de la torre oriental en los diferentes pasos de su proceso constructivo

sugerencia de que la entrada fuera única en época emiral y se ampliaran las torres al interior en época califal, creando una segunda hoja de arco y puerta (Turina 1990). Con menos garantía científica se puede acoger la proposición de una ampliación o “refuerzo” en época cristiana. Únicamente es necesario analizar los restos de supuesto soporte para comprender que la colocación más o menos ocasional de un sillar en la esquina izquierda de la torre oriental,

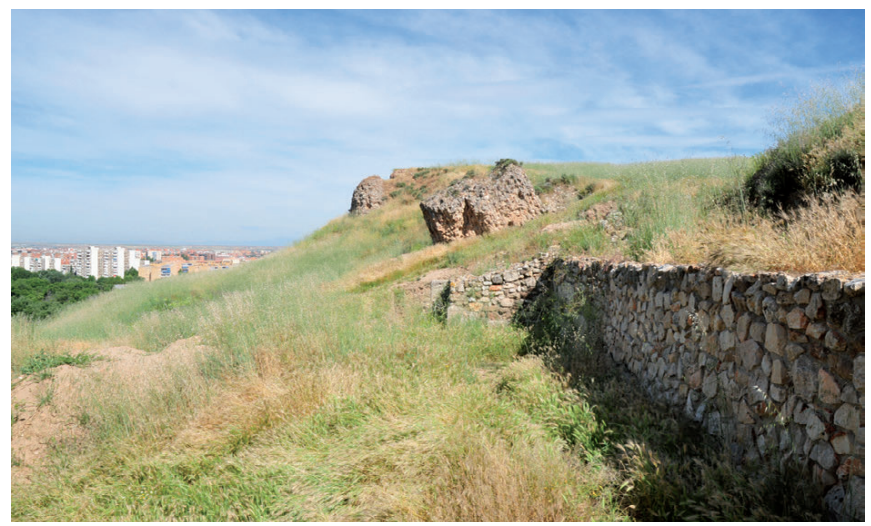

Figura 12. Vista general de la zona de la entrada donde se aprecia el lienzo de muralla rehecho en las primeras campañas de intervención y los restos de las torres 3,4 y 6 . Los aparejos reconstruidos poco tienen que ver con la característica fábrica califal sobre medio metro de relleno, poco tiene que recalzar, por no hacer referencia al conjunto de calicanto de poco más de medio metro cúbico asentado sobre la escarpa original miocena que buza más de 30 grados en sentido sur. Este "refuerzo" no podría sujetarse ni a sí mismo, por lo que difícilmente soportaría una estructura de varias centenas de toneladas (Fig. 13).



Figura 13. Vista de la torre oriental (número 6), antes de la intervención, donde se puede apreciar el derrumbe, adosado a un sillar y a la propia fachada de la torre y consolidado como refuerzo en intervenciones anteriores 


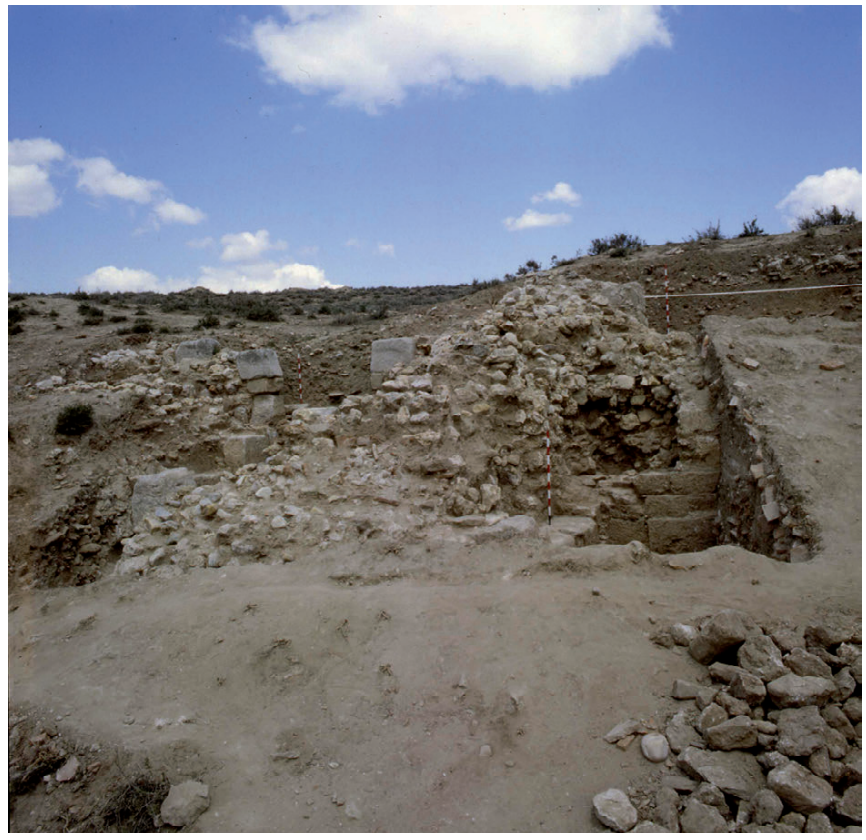

Figura 14. Vista general de la zona de acceso tras su excavación en 1984. Se aprecia el grueso derrumbe de la propia torre que se confundiría en parte con un recalce cristiano en la zona próxima a la esquina oeste de la torre oriental, y que como tal fue consolidado, creando un falso histórico que ha sido corregido en la presente actuación (Foto J. Latova)

La forma de construir era la habitual en la época andalusí. La obra era, por lo tanto, dirigida por un ingeniero jefe (Urafa' al-muhandisin), siguiendo unas pautas y una manera de construir anclada en la tradición y empleando los materiales que dominaban sobre terrenos en los que se sentían cómodos. El dibujo de la qal'at se adapta a la topografía existente, en un pequeño cerro, sobre arenas y margas, es decir, sin una base sólida o consistente sobre la que cimentar. Prevalece la situación de dominio sobre el valle del Henares y su cercanía al corredor sobre otras circunstancias de seguridad en la edilicia. Otros ejemplos como Calatalifa (Pérez Vicente 1990), sobre el cerro que domina el Guadarrama, cimentada sobre un arenero, o incluso Madrid, sobre el cerro que domina el Manzanares y cimentada sobre arcosas de la sierra, certifican este sistema constructivo sólo utilizado por quienes se sienten habituados a este tipo de terreno. El trazado y dibujo se realiza siguiendo el módulo del codo rasasí y se encofra, prácticamente desde la zarpa, para rellenar el interior y macizar las construcciones. Es necesario precisar que no existe, ni se ha documentado, ningún cuerpo de guardia ni estancia en el interior de ninguna de las torres. Si así fuera, se hubiera reflejado en la existencia de una fachada interior o un paramento de mampuesto. Además, el sistema

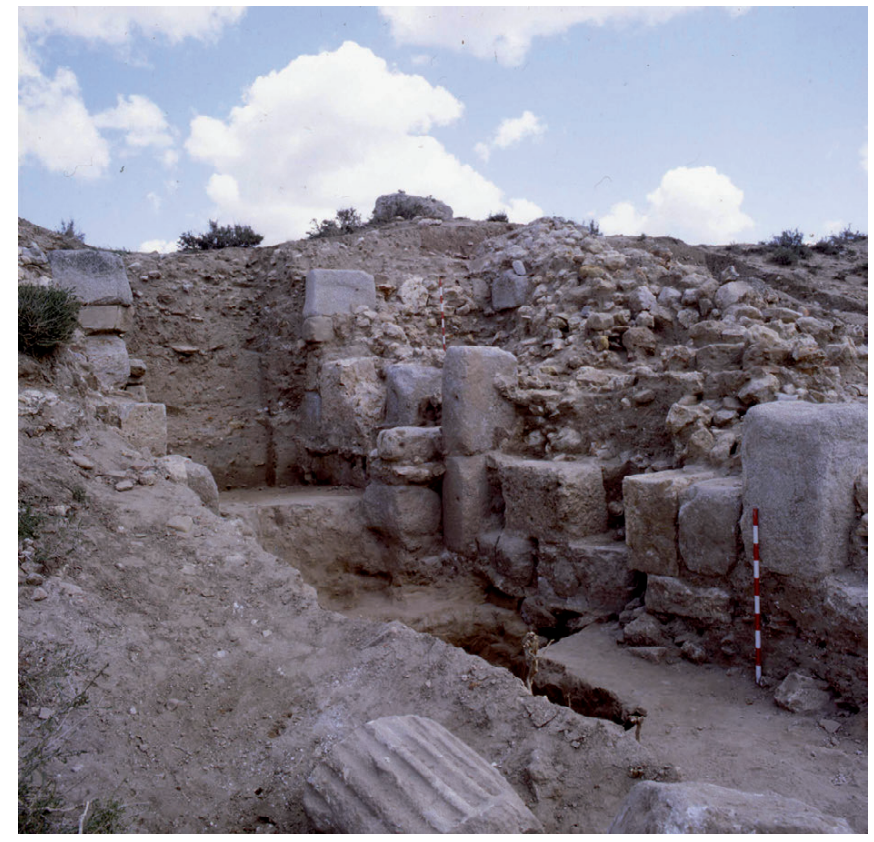

Figura 15. Vista de la torre oriental tras la primera campaña de excavación. No se aprecia corte alguno en las tongadas que suponga la existencia de añadidos posteriores, ni restos fiables de tabiques o fachadas interiores de un hipotético cuerpo de guardia. Se observa con claridad que es una torre maciza cono el resto, que utiliza unas técnicas constructivas propias de ese tipo de edificaciones (Foto J. Latova)

constructivo de tongadas de relleno es incompatible con este tipo de estructuras ${ }^{27}$ (Figs. 14 y 15).

Otras características de la arquitectura militar andalusí aquí representada, además de la sencillez en el trazado, o el arranque de las torres sobre zarpas (Almagro 2008), aparejo de sillería combinado con la argamasa y calicanto, siguiendo el sistema de encofrado sobre base de piedra, etc., son la inclusión de uno o varios aljibes en la zona interior del recinto, o la tendencia a embutir la entrada entre torres alargando el acceso en un túnel interior (Navareño 1988), de doce codos en este caso. El uso, y abuso en ocasiones, de los encofrados obliga al diseño de construcciones cuadradas, rectangulares, o facetadas, en lugar de las construcciones circulares muy difíciles de encofrar. Se localizan paralelos de este tipo de construcciones en fases emirales de Gormaz, por citar un ejemplo.

Pequeñas variaciones se pueden encontrar dependiendo de la pericia del ingeniero (al-muhandis), especialmente en el sentido de la poliorcética referida al arte defensivo, que podía incluir buhederas como en Gormaz (Almagro 2008:

\footnotetext{
${ }^{27}$ La incompatibilidad viene determinada por las dimensiones de la construcción. En una torre de poco más de cuatro codos no se puede debilitar la base con un sistema de encofrados y relleno de calicanto, y cargar con cientos de toneladas el resto de la construcción sobre dicha superficie reducida por el hueco del acceso al cuerpo de guardia.
} 

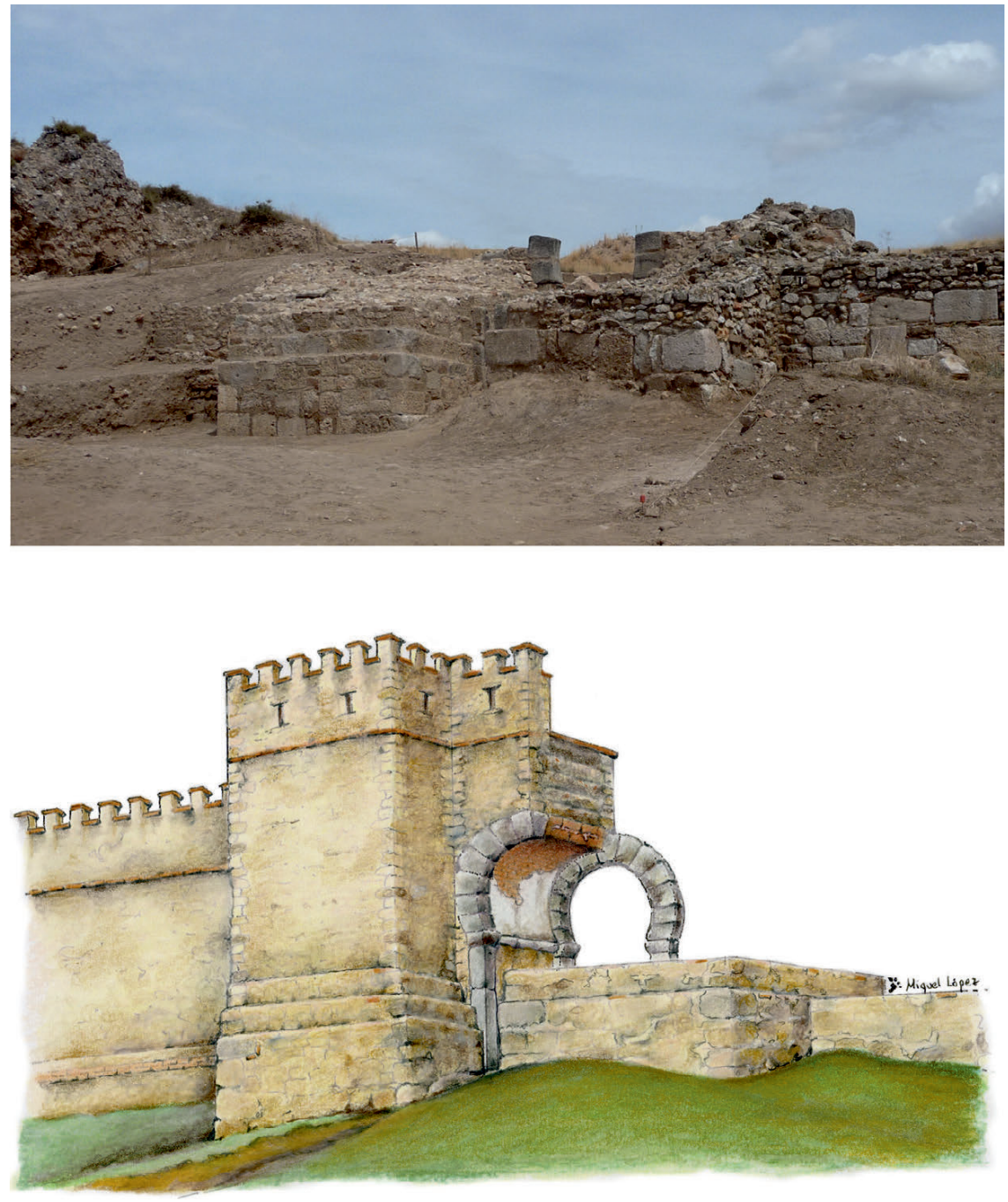

Figura 16. Vista actual tras la intervención y reconstrucción hipotética del acceso a la fortaleza
64), saeteras, matacanes o merlones. En la reconstrucción hipotética que se ilustra (Fig. 16), se combinan los datos arqueológicos, como el diseño, trazado, o alzado en relación a otras torres existentes de la fortaleza, aparejo empleado, rosca de la bóveda de ladrillo según los datos proporcionados de la excavación de 1984 (Turina 1990), con otros datos tipológicos de paralelos encontrados en otras fortalezas como las saeteras (Gormaz) o los merlones representados, característicos de la arquitectura militar andalusí.

Sobre las puertas de acceso, no son muchas las evidencias que han llegado hasta nosotros, sin embargo, se pueden esbozar una serie de conclusiones o reconstruir hipotéticamente la zona de la entrada siguiendo la lógica constructiva. Es evidente que no existe cerco propiamente dicho, sino que es el propio muro el que hace la función. La rotación de la hoja, o de las hojas en este caso, se realiza en quicios, uno superior (gorronera) y otro inferior (durmiente) (de éste último se ha documentado un ejemplar desplazado y reutilizado posteriormente). En ellos encaja el larguero de giro del que sobresalen dos pivotes (sean de una pieza o unidos al tablón posteriormente). De esta manera la puerta queda solapada a haces interiores. Este dato es importante y condiciona la siguiente suposición. El hecho de que las dovelas no tengan galce (o gargol), es decir, el rebaje que serviría de tope a una hoja de puerta, condiciona que el larguero sea evidentemente lo más largo posible de manera que se reduzca al máximo el descuelgue de la hoja. En la figura 17 se puede apreciar cómo una hoja rectangular prolonga en más de un tercio las quicialeras distanciándolas en más de 3 codos y reduciendo así el descuelgue de la madera ${ }^{28}$.

\footnotetext{
28 El quicio está formado por el durmiente donde se embute el espigón, reforzado seguramente con una funda metálica que reduzca el desgaste y facilite el giro de las hojas. Entra dentro de la lógica constructiva igualmente que la funda de hierro se proteja con un tocho de azufre para reducir la corrosión o que el larguero se refuerce igualmente con llantas metálicas a todo lo largo para evitar el pandeo de la madera.
} 


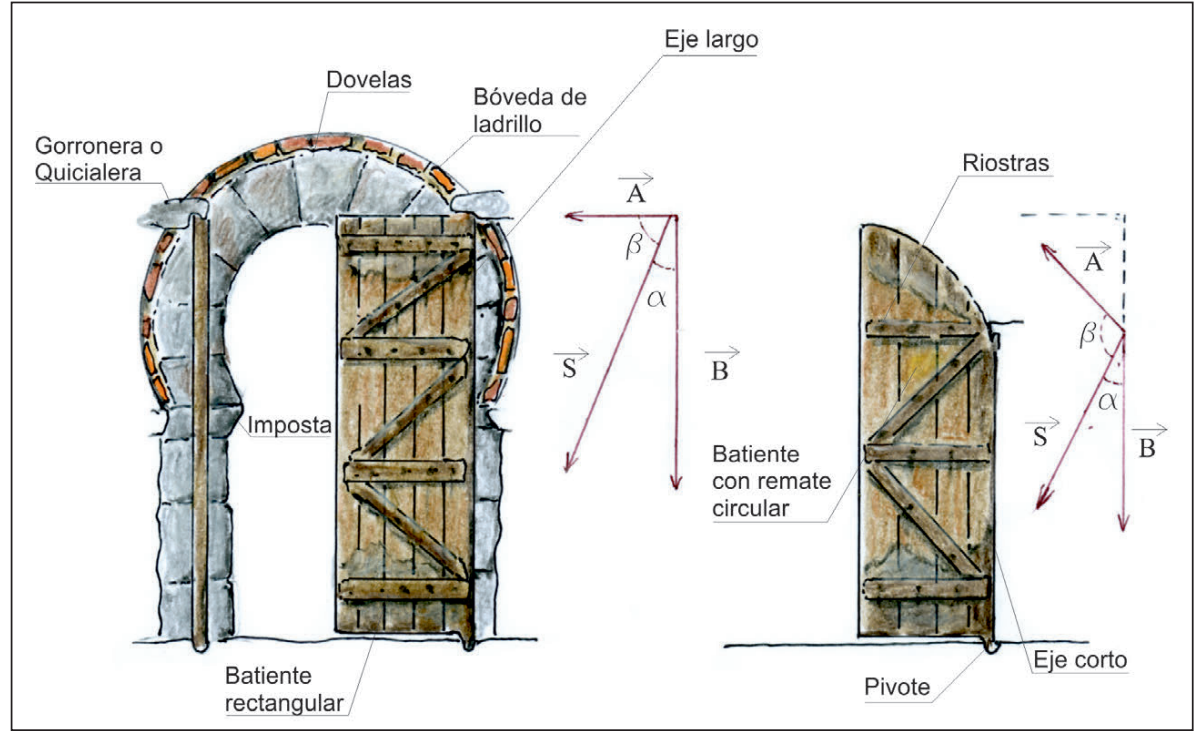

Figura 17. Propuesta de reconstrucción de la zona de entrada. Las hojas rectangulares (nueve codos de altura aproximadamente), reducen en más de un tercio el peso y el empuje de la fuerza resultante (S) al alargar el eje. En el caso del batiente con remate circular, el descuelgue de la madera sería mayor al no existir galces en las dovelas donde se ajusten las puertas
Se puede afirmar con seguridad por lo tanto que la entrada de acceso se compone de dos hojas de arco, que a su vez presentan dos batientes cada una de dos codos de ancho por entre ocho y nueve codos de altura si completamos el desarrollo del arco de herradura. Igualmente, se puede concluir que se formaría cada batiente de tablones de distinto grosor y anchura, armados con riostras de la misma madera. Si se eligiera una madera de densidad media (castaño, roble, etc.), alcanzaría cada elemento los 80 kilos de peso. Existen dos posibilidades de batiente, una con remate circular, que se adaptaría a la bóveda descrita, sobre todo en el primer acceso, y otra de forma rectangular. La opción más simple podría conducirnos directamente al remate adaptado a la bóveda, ante la falta de espacio para el giro sobre el eje. Sin embargo, apostamos sin duda por la opción rectangular, puesto que hay espacio de sobra para ejecutar los 90 grados de giro, como se puede apreciar en la figura 17, y se prolongaría el eje en más de un tercio reduciendo el empuje del peso total en más de 14 kilos y retrasando así el descuelgue de la madera. Si existieran galces o rebajes en las dovelas, dicha resultante no se produciría. En un sistema mecánico, el empuje o peso viene determinado por la suma vectorial de las fuerzas horizontal y vertical con un mismo punto de aplicación y distinta dirección.

El sistema de cierre se refuerza con trancas, como demuestran los mechinales existentes en los paramentos de las torres.

\section{La torre número 9}

De todas las torres existentes, ya sean emergentes o semienterradas, es la número 9 la que merece especial atención debido a sus precarias condiciones de conservación y por sus peculiares características constructivas. En cuanto a su conservación, es necesario realizar una intervención de urgencia lo antes posible, puesto que el fuerte proceso erosivo ha descalzado la cimentación de la edificación. Dicho proceso sigue activo y las grietas abiertas son testigos evidentes del movimiento que está sufriendo la estructura. En poco tiempo se desplomará sobre el camino la reintegración de tapial (tậbiya) realizada, probablemente, en época cristiana. Es especial también por sus características constructivas, derivadas de unos problemas de cimentación que no son nuevos. Los perfiles erosionados son testigos que se dibujan en el escarpe del terreno.

Fue edificada al borde de la meseta sin tener en cuenta la fuerte erosión que sufre la zona. Sobre una pequeña zanja de cimentación se construyó el torreón, macizo, de sillares reutilizados en la base, con una probable zarpa al este, hoy perdida, relleno de cal y canto al interior, en un rápido tránsito del sillar al relleno de argamasa y piedra de pequeño tamaño. En el lado sur se aprecia la altura real de la muralla que apoyaba sobre la fachada. Es probable que el mampuesto y los sillares se utilizasen en la fachada caída. Si fuera toda la construcción de tongadas de calicanto, se habría descalzado seguramente sin perder la fachada. El hecho de que haya caído hace pensar en esa posibilidad, dado que desde un punto de vista defensivo sería más lógico, pero especialmente porque, en lo estrictamente constructivo, si se hubiese edificado encofrando en bloque se habría socavado el cimiento sin perder la línea delantera, al presentar un conjunto compacto de peso similar, sin superar los $1800 \mathrm{~kg}$ por $\mathrm{m}^{3}$. Es fácil el desplome de una línea de sillar y mampuesto que supera los $2400 \mathrm{~kg}$ de peso en fachada rompiendo la homogeneidad 
de la construcción y presentando una línea de contacto débil entre frente y torre con una diferencia de $600 \mathrm{~kg}$ por $\mathrm{m}^{3}$ entre uno y otra (Azuar 1987).

La torre estuvo un tiempo sin delantera, puesto que se aprecia en el perfil que la erosión continuó antes de su reparación en época cristiana. Si la fortaleza estuvo en activo algo más de seiscientos años, es de suponer que probablemente en un momento tardío se decidió su restauración. Ante la falta de material constructivo sólido, se opta por el tapial para recrecer la fachada perdida. La nueva construcción se cimienta casi dos metros por debajo de la cota original y se rellena de arcilla el encofrado realizado al efecto.

Desde la época de abandono han transcurrido más de setecientos años en los que ha continuado el proceso erosivo, descalzándose de nuevo la edificación, y perdiendo parte del tapial en las zonas de chaflán donde es más débil el añadido ${ }^{29}$ (Fig. 18).

\footnotetext{
29 Este análisis forma parte del estudio previo a la excavación arqueológica prevista en una próxima campaña, y se centra exclusivamente en los restos visibles de la torre.
}

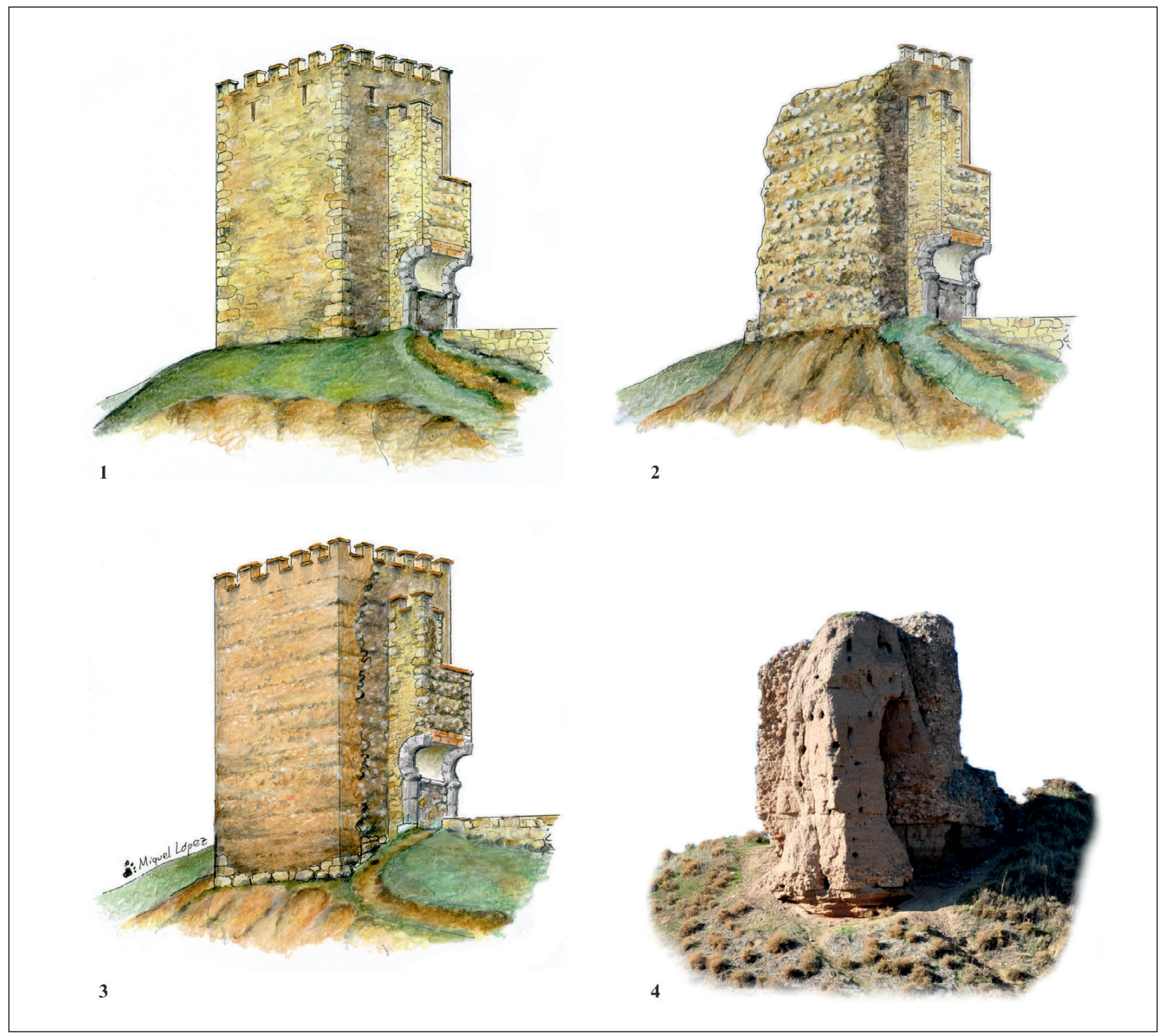

Figura 18. Reconstrucción hipotética de las diferentes fases constructivas de la torre número 9. 1. Reconstrucción hipotética del cubo número 9, con arranque de muralla y poterna; 2. Derrumbe de fachada por fallo estructural tras el proceso erosivo de su base de fundación; 3. Reconstrucción tardía de tapial en una posición adelantada, sobre una nueva base de cimentación; 4 . Vista actual tras el derrumbe parcial de la torre y nuevo descalce de la fachada que pone en peligro de modo inminente la conservación de la construcción 


\section{SÍ NTESIS HISTÓRI CA DE LAS I NTERVENCI ONES Y PROYECTO DE EJECUCIÓN}

En la actualidad existe un proyecto de intervención con el fin de recuperar la fortaleza. Aunque sólo se han realizado tres campañas de intervención, ya se pueden apreciar los resultados. Toda intervención va dirigida a mejorar la exhibición y comprensión del yacimiento, aplicando unos criterios de restauración y conservación vigentes y coherentes con la obra.

Las agresiones de carácter antrópico que más han alterado la visión del conjunto han sido las ejecutadas en campañas de restauración por parte de la Dirección General de Bellas Artes en 1984 y de la Escuela Taller de Alcalá de Henares en 2006.

La primera de ellas fue la más grave, al proyectar una actuación dura y agresiva, para realizar una obra que supuestamente iba a proteger las ruinas existentes. La segunda intervención fue dañina por continuista.

Durante la ejecución de las obras no se realizó un estudio previo del estado de conservación, y no se detuvo el proceso de deterioro del yacimiento. La restauración se centró en el recrecimiento indiscriminado del paramento exterior y la realización de drenajes como actuación de conservación preventiva. Es preciso señalar que el drenaje natural funciona perfectamente al tener una acusada pendiente el lugar. Si se hubiera realizado dicho estudio, se habrían coronado todas las cabeceras de muros y torres descubiertas que dejaban expuestas a la destrucción las argamasas de cal muertas y "descarbonatadas” (Fig. 19).

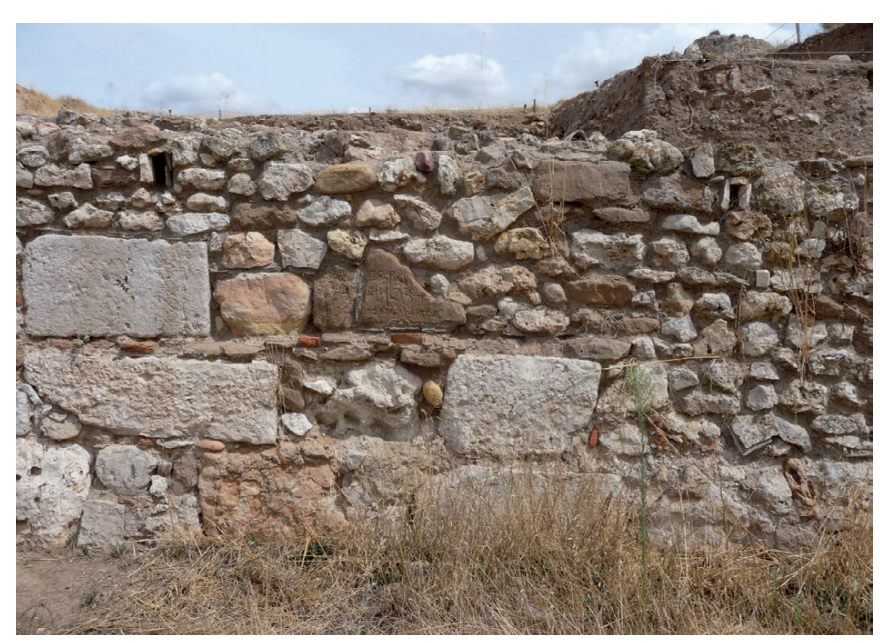

Figura 19. Intervención realizada en los años 80. Lienzo de muralla donde se aprecia abajo a la izquierda el aparejo original concertado de sillares, mampuesto y ladrillo. Arriba a la derecha, restitución de piedra sin carear, acabada con un pretil y dos mechinales de desagüe que remata la zona superior como "obra acabada"
El error de interpretación arqueológica en los supuestos añadidos tardíos en la torre oriental desembocó en la consolidación precaria de un derrumbe parcial de la estructura que no hacía sino desvirtuar aún más la construcción.

El resultado desde un punto de vista expositivo no fue acertado, al recrear una planta que no tiene que ver con las edificaciones andalusíes. El paramento exterior de la muralla se potenció, mostrando una reintegración que era el todo de una parte y no la parte de un todo como aconsejan las normas internacionales de conservación. Se creó un pretil artificial en la muralla al interior $\mathrm{y}$ al exterior de $50 \mathrm{~cm}$ que contraviene todas las normas poliorcéticas de edificación y se realizaron unos mechinales de desagües en la fachada sin criterio de referencia preexistente. El recrecimiento de la muralla se hizo con mampuesto concertado de caliza, sin respetar el original que era el concertado de sillares y mampuesto con nivelación de tongadas de ladrillo cocido, a la vez que se obviaron las zarpas tan características de la época en las zonas de pendiente. La zanja de cemento intramuros, a modo de canaleta de drenaje, descontextualiza definitivamente la muralla con la estratigrafía del relleno. Todo ello descoloca al visitante, especialmente al rematar la zona superior como bardas de obra acabada, haciendo incomprensible la exhibición del yacimiento, que ya nada tiene que ver con la característica edilicia musulmana del momento. Poco quedaba del aparejo mixto de fábrica, del trazado defensivo o de las verdaderas dimensiones de la construcción.

El presente proyecto de intervención trata de recuperar la dignidad perdida por el paso del tiempo, el abandono y, sobre todo, el desacierto demostrado en las campañas de restauración anteriores, desenfocadas en objetivos superficiales y diseñadas para servir de coartada a interpretaciones erróneas.

En la actual intervención de excavación y restauración, se elaboró un estudio previo del estado de conservación, que pronto dejó en evidencia la "descarbonatación" de los morteros tras su exhumación en la década de los ochenta, por lo que se realizó la coronación de una hilada de protección en todas las cabeceras de los muros, especialmente en la torre occidental, que presentaba una gran extensión deteriorada (Fig. 20). Se hicieron drenajes naturales y se recuperaron otros originales para no desvirtuar la obra primitiva. El resto de actuaciones se encaminaron a garantizar la seguridad del visitante, reduciendo perfiles estratigráficos, o vallando zonas de exhibición tras crear itinerarios y accesos. 


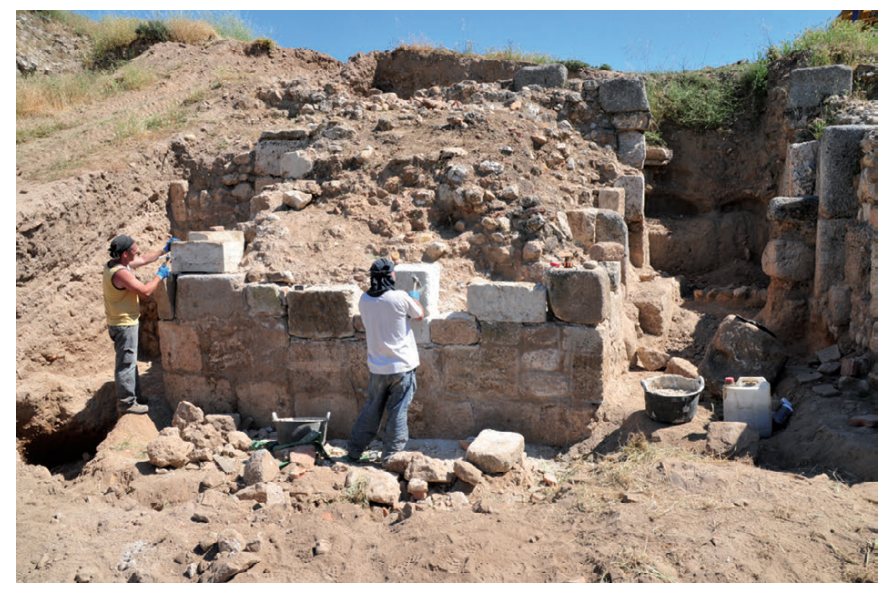

Figura 20. Vista del proceso de restauración de la torre occidental. Se recrecieron varias hiladas para reducir la pendiente interior de más del $40 \%$ que provocaba el lavado continuo de los morteros por escorrentías pluviales. Los aparejos del recrecido respetan la edilicia califal típica sin llevar a error al visitante como en intervenciones anteriores

\section{La recuperación de la dignidad perdida}

Es evidente que se trata de un yacimiento maltratado por el tiempo y por el hombre. El asentamiento edificado sobre terrenos inestables, así como los materiales constructivos utilizados, sobre todo en el interior, de muros de mampuesto recibido en seco con arcilla, no ayuda a garantizar un estado de conservación idóneo. De igual modo, las propias características defensivas del lugar, susceptibles de ser atacadas y demolidas, como lo atestiguan los numerosos bolaños y piezas de artillería localizadas ${ }^{30}$, o la tradición militar del entorno al convertir la zona en campo de tiro,

${ }^{30}$ En contextos claramente bajomedievales. La maquinaria de guerra documentada se desarrolla a partir del siglo XIII. tampoco es el mejor escenario de preservación para un yacimiento. La intención reconstructora de las primeras investigaciones hizo más daño, al realizarse sin criterio, desvirtuando por completo las características constructivas y la propia identidad de la fortaleza.

La continua actividad y desarrollo poblacional, desde la ocupación musulmana hasta el abandono en época cristiana, solapa el testimonio de múltiples reformas de mayor o menor envergadura a nivel particular o a nivel supraestructural de trazado y diseño definitivo.

Todas las intervenciones de reformas históricas realizadas en la fortaleza marcan la diferencia entre unas técnicas constructivas propias de la fábrica característica de época andalusí y otro tipo de reformas o ampliaciones de época cristiana donde se generaliza el aparejo mixto de piedra y caliza, como se puede observar en la torre albarrana, por citar un ejemplo.

Es fundamental, por tanto evitar el falso histórico y mantener el respeto a cada fase de intervención, ya de por sí compleja para el visitante, sea andalusí o posterior, sin añadir nuevos tipos de aparejos del siglo XX o $\mathrm{XXI}$, huyendo de un protagonismo que no nos pertenece y que no hace sino despreciar el original y confundir al neófito. (Fig. 21).

\section{AGRADECI MI ENTOS}

Los trabajos han sido promovidos por la Dirección General de Patrimonio Histórico de la Comunidad de Madrid, enmarcadas en el Plan de Yacimientos Visitables. Todas las actuaciones han sido coordinadas por Inmaculada Rus, técnico de la citada Dirección General, a quien agradecemos, el interés demostrado en la puesta en valor del yacimiento. El levantamiento topográfico,
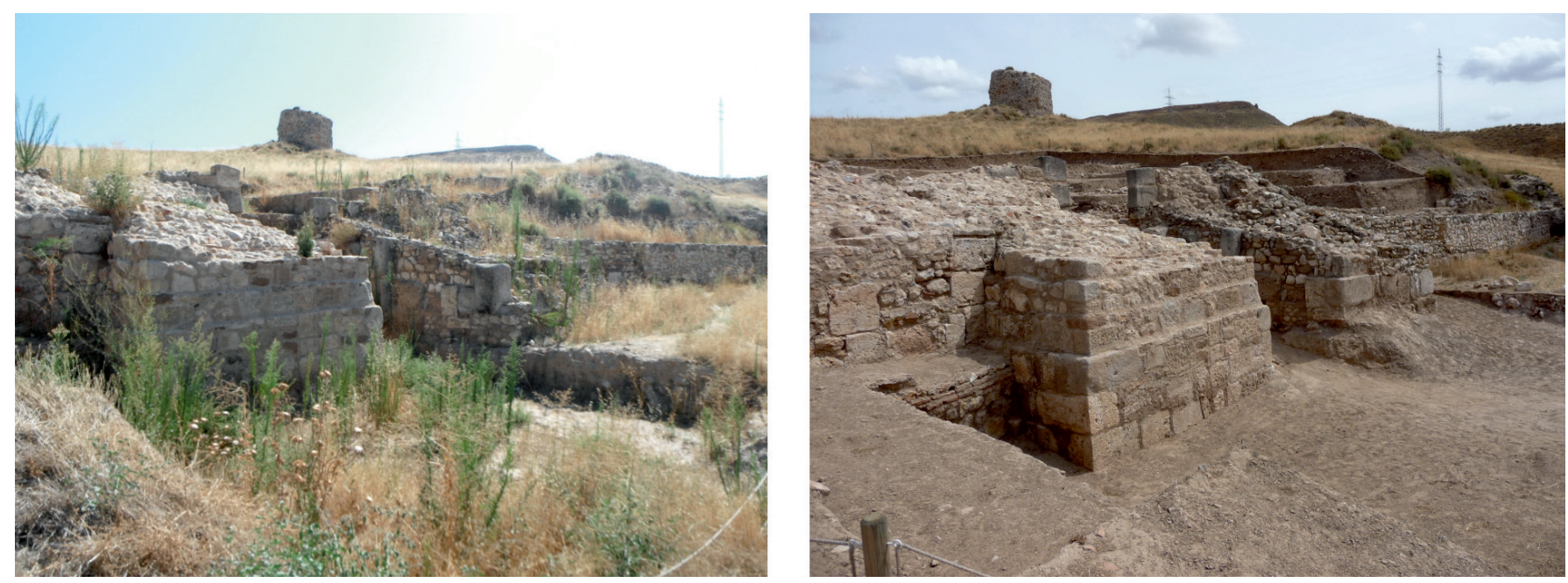

Figura 21. Vista general de la zona de la entrada antes y después de la intervención 
caracterización geométrica de la fortaleza, así como las plantas y secciones de las estructuras, han sido realizadas por las empresas Actividades y Servicios Fotográficos y GIM Geomatics.

\section{Bibliografía}

Almagro, A. 2008: "La puerta califal del castillo de Gormaz", Arqueología de la Arquitectura, 5, pp. 55-77.

Azuar Ruiz, R. 1987: “El castillo en época medieval”, Guía de monumentos romanos, pp. 58-71. Valencia.

Castillo Oreja, M. A. 2006: Guía de Alcalá de Henares. La ciudad histórica. Madrid.

De Diego Pareja, L. M y Canalda Cámara, J. C. 2001: Alcalá de Henares, crónica general. Guadalajara.

De Diego Pareja, L. M. 2003: "El castillo de Alcalá la Vieja y su situación en la línea defensiva del valle del Henares”, Alcalá de Henares páginas de su historia: XII Curso de Historia, Arte y Cultura, pp. 33-55. Alcalá de Henares.

García Lledó, F. J. 1991: "Visigodos y etapa musulmana", VII Curso de Historia y Arte de Alcalá de Henares, pp. 13-17. Alcalá de Henares.

García Lledó, F. J. 1996: "Complutum visigoda e islámica”, Alcalá: apuntes de historia y arte, pp. 13-18. Alcalá de Henares.

García Lledó, F. J., 2008: "La cultura material medieval en Alcalá. Los musulmanes”, en Valle Martín, J. L. (dir.), La cultura material de nuestro entorno y su interpretación histórica, pp. 155-171. Madrid.

González, J. 1975: Repoblación de Castilla la Nueva, Madrid.

Herrera Casado, A. 1985: "La Marca Media de Al-Andalus en tierras de Guadalajara”, Wad-al-Hayara, 12, pp. 9-26.

Ibn 'Id̄ārī 1904: Histoire de l'Afrique et de l'Espagne intitulée al-Bayano'l-lMogrib. Fagnan, E. (trad. y anotado). Argel.

Lévi-Provençal. E. 1982: España musulmana hasta la caída del califato de Córdoba (711-1031 de J.C.), vol. IV: Historia de España, dirigida por Ramón Menéndez Pidal. Madrid (primera edición, 1950).

Márquez Bueno, S. y Gurriarán Daza, P. 2008: "Recursos formales y constructivos en la arquitectura militar almohade de al-Ándalus”, Arqueología de la arquitectura, 5, pp. 115-134.

Martín Escorza, C. 1979: "Fallas y fracturas en las capas miocenas de Alcalá de Henares (Madrid)”, Estudios geológicos, 35, Madrid.

Martínez Enamorado, V., Martínez Salvador, C. y Bellón Aguilera, J. 2007: "A vueltas con la cronología del edificio del castillejo de Monteagudo, Murcia: estudio de un epígrafe con el lema de los nazaríes y reflexiones cobre la metrología de sus tapias constructivas”, Verdolay, 10, pp. 225-235.

Monjó Carrió, J. 1988: "La evolución de la arquitectura de la tierra en España”, en Encuentros internacionales de la arquitectura de tierra, pp. 126-145. Madrid.

Navareño Mateos, A. 1988: "El castillo bajomedieval. Arquitectura y táctica militar”, en Gladius, Vol. Especial, Actas 1er. Simposio Nacional, "Las armas en la Historia“, pp. 113-152.

Olmo Enciso, L. 2011: "De Celtiberia a Santabariyya: la transformación del espacio entre la época visigoda y la formación de la sociedad andalusí”, en 711 Arqueología e Historia entre dos mundos, vol. II, Zona Arqueológica, 15, pp. 39-62. Alcalá de Henares.

Pavón Maldonado, B. 1982: Alcalá de Henares medieval. Arte islámico y mudéjar. Madrid-Alcalá de Henares.

Pérez Vicente, D. 1990: "Excavaciones arqueológicas en Calatalifa”, en Madrid del siglo IX al XI, pp. 141-144. Madrid.

Presas Vías, M., Serrano, E., y Torra, M. 2009: "Materiales cerámicos estratificados (siglos IX-XVI) en el Reino de Toledo", en Zozaya, J., Retuerce, M., Hervás, M.A. y De Juan, A. (eds.), Actas del VIII Congreso Internacional de Cerámica Medieval en el Mediterráneo, Ciudad Real (Almagro, 2006), pp. 805-824. Ciudad Real.
Ramirez Hernández, C. 1998: "Qal'at 'Abd al-Salam y la frontera media de al-Andalus”, en VI Encuentro de Historiadores del Valle del Henares, pp. 75-92. Alcalá de Henares.

Rosselló Bordoy, G. 2002: “Cerámica califal, cerámicas periféricas. Una aproximación a la cerámica andalusí de los siglos X-XI”, en Al-Andalus Omeya, pp. 67-104. Córdoba.

Sánchez Montes, A. L. 1992: “Arqueología de Alcalá de Henares”, en La Casa de Diego Torres. Arqueología, Historia y Rehabilitación, pp. 11-50. Madrid.

Sepulcre Aguilar, A. 2003: "Tópicos comunes en la elaboración y uso de los morteros de restauración de fábrica”, Pátina, II, 12, pp. 29-39.

Serrano, E., Torra, M., Castro, M. y Sánchez, A. 2004: "Excavaciones en Guadalajara: secuencia andalusí desde época emiral a taifa y presentación de un singular conjunto numismático”, Arqueología y Territorio Medieval, 11, 1, pp. 79-113.

Souto, J. A. 1997: "La práctica y la profesión del artista en el Islam, arquitectos y constructores en el Al-Andalus omeya”, Espacio tiempo y forma, serie VII, Historia del Arte, 10, pp. 11-34.

Torres Balbás, L. 1959: "Estudios de arqueología e historia urbana. Complutum, Qal ‘at 'Abd al-Salam y Alcalá de Henares”, Boletín de la Real Academia de la Historia, CXLIV, pp. 155-188.

Turina Gómez, A. 1985: "Alcalá medieval", en I Curso de Historia, Arte y Cultura de Alcalá de Henares (sin paginar). Alcalá de Henares.

Turina Gómez, A. 1990: "El castillo de Alcalá de Henares", en Madrid del s. IX al XI, pp. 189-194. Madrid.

Vallvé, J. 1976: "Notas de metrología hispano-árabe. El codo en la España musulmana”, Al-Andalus, XLI, 2, pp. 339-354.

Vázquez Madruga, M. J. 1988: “Alcalá islámica”, en Resumen de las Conferencias del IV Curso de Historia, Arte y Cultura de Alcalá de Henares, pp. 17-21. Alcalá de Henares.

Vigil-Escalera Guirado, A. 2009: "Sepulturas, huertos y radiocarbono (siglos VIII-XIII d.C.). El proceso de islamización en el medio rural del centro peninsular y otras cuestiones”, Studia Historica, Historia Medieval, 27, pp. 97-118.

Vigil-Escalera Guirado, A. 2011: "Formas de poblamiento rural en torno al 711: documentación arqueológica del centro peninsular", en 711 Arqueología e Historia entre dos mundos, vol. II. Zona Arqueológica, 15, pp. 189-201. Alcalá de Henares.

Zozaya Stabel-Hansen, J. 1980: "La islamización en la provincia de Madrid”, en II Jornadas de Estudios sobre la provincia de Madrid, pp. 77-83. Madrid.

Zozaya Stabel-Hansen, J. 1983: "Excavaciones en la fortaleza de Qal'at ‘Abd-al-Salam (Alcalá de Henares, Madrid)”, en Noticiario Arqueológico Hispánico, 17, pp. 411-529. Madrid.

Zozaya Stabel-Hansen, J. 1991: "Recientes estudios sobre la arqueología andalusí: la frontera media”, en Aragón en la Edad Media, IX , pp. 371388. Zaragoza.

Zozaya Stabel-Hansen, J. 1992: "Las fortificaciones de al-Andalus", en AlAndalus, las artes islámicas en España, pp. 63-73. Madrid

\section{Trabajos y estudios inéditos citados en texto}

Silva, P. G. 1988: El cuaternario del sector centro-meridional de la cuenca de Madrid: aspectos geomorfológicos y geotectónicos. Tesis de licenciatura inédita. Facultad de Geología, Universidad Complutense de Madrid, Madrid.

Vega Miguel, J. J, y Sánchez Montes, A. L. 2005: Informe final. Intervención arqueológica en el recinto de Alcalá la Vieja de Alcalá de Henares (Madrid). Campaña 2003, Informe inédito depositado en la Dirección General de Patrimonio Histórico de la Comunidad de Madrid, Madrid.

Vega Miguel, J. J, y Sánchez Montes, A. L. 2009: Informe de las intervenciones arqueológicas realizadas en la ciudadela hispanomusulmana de Alcalá la Vieja, Alcalá de Henares (Madrid). Campaña 2006, Informe inédito depositado en la Dirección General de Patrimonio Histórico de la Comunidad de Madrid, Madrid. 